\title{
Sulfatase 1 Promotes the Motor Neuron-to-Oligodendrocyte Fate Switch by Activating Shh Signaling in Olig2 Progenitors of the Embryonic Ventral Spinal Cord
}

\author{
Yacine Touahri, Nathalie Escalas, Bertrand Benazeraf, Philippe Cochard, Cathy Danesin, and Cathy Soula \\ University of Toulouse, Center of Developmental Biology, F-31062 Toulouse, France
}

In the developing ventral spinal cord, motor neurons (MNs) and oligodendrocyte precursor cells (OPCs) are sequentially generated from a common pool of neural progenitors included in the so-called pMN domain characterized by Olig2 expression. Here, we establish that the secreted Sulfatase 1 (Sulf1) is a major component of the mechanism that causes these progenitors to stop producing MNs and change their fate to generate OPCs. We show that specification of OPCs is severely affected in sulf1-deficient mouse embryos. This defect does not rely on abnormal patterning of the spinal cord or failure in maintenance of pMN progenitors at the onset of OPC specification. Instead, the efficiency of OPC induction is reduced, only few Olig2 progenitors are recruited to generate OPCs, meanwhile they continue to produce MNs beyond the normal timing of the neuroglial switch. Using the chicken embryo, we show that Sulf1 activity is required precisely at the stage of the MN-to-OPC fate switch. Finally, we bring arguments supporting the view that Sulf1 controls the level of Sonic Hedgehog (Shh) signaling activity, behaving as an enhancer rather than an obligatory component in the Shh pathway. Our study provides additional insights into the temporal control of Olig2 progenitor cell fate change by the identification of Sulf1 as an extracellular timing signal in the ventral spinal cord.

\section{Introduction}

Neurons and glial cells of the CNS originate from neural progenitors that differentiate in a highly specific manner, both spatially and temporally. The spinal cord has served as an excellent model for studying both diversity and successive waves of neural cell generation. Under the influence of patterning signals, the neural tube is segmented into distinct progenitor domains, each dedicated to generate a particular neuronal and glial cell population. In the ventral neural tube, depending on both its concentration and timing of exposure, Sonic Hedgehog (Shh) regulates expression of transcription factors that demarcate five progenitor re-

\footnotetext{
Received July 25, 2012; revised 0ct. 2, 2012; accepted 0ct. 21, 2012.

Author contributions: C.S. designed research; Y.T., N.E., B.B., and C.D. performed research; Y.T., N.E., B.B., P.C., C.D., and C.S. analyzed data; C.S. wrote the paper.

This work in the laboratory of C.S. was supported by grants from the National Agency for Research, Association for Research on Multiple Sclerosis (ARSEP), National Center of Scientific Research, and University of Toulouse. Y.T. was supported by doctoral grants from Ministry of National Education, Research, and Technology and ARSEP. We acknowledge the Developmental Studies Hybridoma Bank, developed under the auspice of National Institute of Child Health and Human Development and maintained by the University of lowa, Department of Biological Sciences (lowa (ity, IA), for supplying monoclonal antibodies. We are grateful to colleagues in the Center for Developmental Biology for help, encouragement, and advice, especially B. Glise and F. Pituello for helpful discussions and critical reading of this manuscript. We especially thank X. Ai and C. Emerson for their generous sharing of the sulf1 mutant line and R. Zeller for kindly sharing shh mutant line. We thank Yannick Carrier and Audrey Montigny for invaluable technical assistance and Jacques Auriol for assistance with mouse breeding and care. We are grateful to D. Anderson, F. Guillemot, A. Joyner, M. Scott, C. Tabin, and A.Vincent who kindly provided us with valuable reagents. We thank the Toulouse Regional Imaging Platform for technical assistance in confocal microscopy.

The authors declare no competing financial interests.

Correspondence should be addressed to Cathy Soula, University of Toulouse, Center for Developmental Biology, Coeducational Research Unit 5547, National Center of Scientific Research/University Paul Sabatier, 118 Route de Narbonne, F-31062 Toulouse, France. E-mail: catherine.soula@univ-tlse3.fr.

DOI:10.1523/JNEUROSCI.3553-12.2012

Copyright $\odot 2012$ the authors $\quad 0270-6474 / 12 / 3218018-17 \$ 15.00 / 0$
}

gions (Briscoe and Novitch, 2008). Among them, the pMN domain, marked by expression of Olig2, first generates all of the motor neurons (MNs) and changes with time to produce most oligodendrocyte precursor cells (OPCs) of the spinal cord (Rowitch, 2004). How this developmental switch from production of MNs to OPCs is controlled has been partially elucidated, and both cell-intrinsic and cell-extrinsic mechanisms were shown to underlie this coordination (Kessaris et al., 2008; Rowitch and Kriegstein, 2010). Strikingly, signaling factors that control OPC generation in the spinal cord have much in common with those that instruct neural progenitors to become specialized neurons. In the ventral spinal cord, the decision to produce OPCs, at a time long after the dorsoventral neuronal patterning is completed, still depends on Shh activity (Poncet et al., 1996; Pringle et al., 1996; Orentas et al., 1999; Soula et al., 2001; Agius et al., 2004; Park et al., 2004). In chicken, the specificity in the response to Shh relies on its level of activity, optimal OPC induction being driven at higher doses of Shh than those required to generate MNs (Soula et al., 2001; Danesin et al., 2006). Accordingly, a temporal variation in Shh distribution, concentrating at the apical surface of ventral neural progenitors, has been proposed to trigger this cell fate change (Danesin et al., 2006). Other signaling molecules, such as FGFs, have also been recognized as OPC inducers, in particular in the dorsal spinal cord, but do not seem to be active in its ventral counterpart (Chandran et al., 2003; Kessaris et al., 2004). Finally, the dorsalizing factors, BMPs and Wnt, by repressing the OPC fate, are also regulators of the decision to make neurons or OPCs (Mekki-Dauriac et al., 2002; Miller et al., 2004; Bilican et al., 2008; Langseth et al., 2010). How these signaling pathways are temporally controlled to confer distinct identities to 
neural progenitors remains an opened question. Sulfatase 1 (Sulf1), a regulator of the heparan sulfate proteoglycan (HSPG) sulfation "code" (Dhoot et al., 2001; Morimoto-Tomita et al., 2002; Ai et al., 2006; Lamanna et al., 2006), represents a good candidate to orchestrate such temporal variations (BraquartVarnier et al., 2004; Danesin et al., 2006). HSPGs are crucial players in numerous signaling pathways, and Sulf1, by remodeling their 6O-sulfation pattern, is recognized as a key regulator of their interactions with signaling molecules, including Hedgehog proteins (Danesin et al., 2006; Ratzka et al., 2008; Wojcinski et al., 2011). A possible relationship between Sulf1 activity and the MNto-OPC switch was initially proposed based on the tight correlation between Sulf1 dynamic spatiotemporal expression pattern and the timing of Shh-dependent OPC induction in the chicken ventral spinal cord (Braquart-Varnier et al., 2004; Danesin et al., 2006). However, direct evidences for Sulf1 function in regulating OPC generation were still lacking.

In this study, we show that Sulf1 activity is required for proper specification of OPCs in the embryonic ventral spinal cord. Our results support a model whereby Sulf1 acts as a temporal regulator of Shh activity that triggers Olig2 progenitor cell fate change, from the production of MNs to that of OPCs.

\section{Materials and Methods}

\section{Animals}

Experiments were performed in accordance with the European Community guiding principles on the care and use of animals (86/609/CEE; Official Journal of the European Communities number L358, December 18, 1986), French decree number 97/748 of October 19, 1987 (Official Journal of the French Republic, October 20, 1987), and the recommendations of the National Center of Scientific Research. Generation of Shh and Sulf1 mutant mouse lines were reported previously (St-Jacques et al., 1998; Ai et al., 2007). Mutant mice were maintained as heterozygous stocks in C57BL/6 genetic background and crossed to generate different mutant combinations. For genetic interaction experiments, sulf1 ${ }^{-/-}$and $\operatorname{shh}^{+/-}$mice were mated to generate sulf1 ${ }^{+/-} ;$sh $^{+/-}$heterozygous mice, which were further crossed with sulf1 $1^{-1-}$ mice to generate sulf1 ${ }^{-1-}$; $\operatorname{shh}^{+/-}$and sulf1 ${ }^{-/-} ; \mathrm{shh}^{+/+}$littermate embryos. Genotyping was performed by DNA extraction from tails followed by PCR (St-Jacques et al., 1998; Ai et al., 2007). Embryonic day 0.5 (E0.5) was the day vaginal plugs were found. Mutant and control mice of either sex were analyzed from the same litters, facilitating comparisons among the genotypes. The stages of embryos with different genotypes were further matched using size and shape of limb buds. Fertilized White Leghorn chicken eggs, obtained from a commercial source, were incubated at $38^{\circ} \mathrm{C}$ until they reached the appropriate stages (Hamburger and Hamilton, 1992).

\section{Staining procedures}

Tissue preparation. Mouse and chicken embryos or flat-mounted explants were fixed in $4 \%$ paraformaldehyde (PFA) in PBS overnight at $4^{\circ} \mathrm{C}$, dehydrated, and stored in $100 \%$ ethanol at $-20^{\circ} \mathrm{C}$. Tissues were then sectioned at $60-80 \mu \mathrm{m}$ using a vibratome (Microm). In all experiments, sections were performed at the cervico-brachial level. For detection of Sulf1 on spinal cord or explant sections, we used the previously reported protocol (Gritli-Linde et al., 2001; Braquart-Varnier et al., 2004) that allows preservation of extracellular matrix molecules. Specimens were fixed overnight in cold 95\% ethanol and 1\% acetic acid (Sainte Marie's solution) and then washed in 95\% ethanol.

Immunostaining. For immunofluorescence analysis, chicken and mouse tissues were processed as described previously (Agius et al., 2004; Danesin et al., 2006), except that horse serum (10\%) was used to block mouse spinal cord sections. Primary antibodies were applied overnight at $4^{\circ} \mathrm{C}$. Secondary antibodies were applied at room temperature for $1 \mathrm{~h}$. The antibodies used were as follows: rabbit anti-Olig2 at 1:500 (Millipore Bioscience Research Reagents); goat anti-Sox10 at 1:500 and anti-Nkx2.2 at 1:250 (Santa Cruz Biotechnology); rat anti-BrdU at 1:1000 (AbD Serotec); and rabbit anti-GFP at 1:500 (Torrey Pines Scientific). All the following monoclonal antibodies (culture supernatants) were obtained from Developmental Studies Hybridoma Bank: anti-MNR2 at 1:8 (Tanabe et al., 1998), anti-Nkx2.2 at 1:2 (Ericson et al., 1996), and antiIslet1 at 1:3 (Ericson et al., 1992). Alexa Fluor 488, 555, or 647 goat anti-rabbit, goat anti-mouse, donkey anti-goat, or donkey anti-rat at 1:500 were from Invitrogen. Rabbit anti-Sulf1 antibodies, directed against the hydrophilic domain of chicken and mouse Sulf1, were generated as described previously and used diluted at 1:200 for immunodetection experiments (Braquart-Varnier et al., 2004; Ai et al., 2007).

In situ hybridization. In situ hybridization (ISH) was performed on vibratome sections of mouse and chicken embryos and spinal cord explants either by hand or automatically (InsituPro, formerly Intavis) using the whole-mount ISH protocol described previously (Braquart-Varnier et al., 2004; Danesin et al., 2006). Digoxigenin (DIG)-labeled sense and antisense RNA probes were synthesized using T3 and T7 polymerases. RNA labeled probes were detected by an alkaline-phosphatase-coupled antibody (Roche Diagnostics), and nitroblue tetrazolium/5-bromo-4chloro-3-indolyl phosphate (NBT/BCIP) was used as a chromogenic substrate for alkaline phosphatase (Boehringer Mannheim). Sections were processed for two-color double hybridization using DIG- and fluorescein-labeled antisense riboprobes for sulf1 and either patched1 ( $p t c 1$ ) or gli1. DIG-labeled probes were revealed in dark blue using NBT/ BCIP solution, whereas fluorescein-labeled probes were revealed in red using INT/BCIP solution, following standard procedure. Stained sections were digitized on a Nikon microscope, and images were manipulated using Adobe Photoshop (Adobe Systems). The following gene probes were used: chick and mouse $p t c 1$ [provided by C. Tabin (Harvard Medical School, Boston, MA) and M. Scott (Standford University School of Medicine, Standford, CA), respectively], chick and mouse gli1 (provided by C. Tabin and A. Joyner, Sloan-Kettering Institute, New York, NY, respectively), mouse ebf2 (a gift from A. Vincent, Center fo Developmental Biology, Toulouse, France), mouse ngn2 (provided by F. Guillemot, National Institute for Medical Research, Mill Hill, London, UK), sulf1 (provided by X. Ai, Boston University School of Medicine, Boston, MA), and plp/dm20 (a gift from J. L. Thomas, Paris, France). Counterstaining of Olig2 was performed after color development after a postfixation step in 4\% PFA for $1 \mathrm{~h}$.

\section{Isolation and culture of neural tissues}

Flat-mount preparations of spinal cord explants were cultivated using an organotypic culture system described previously (Agius et al., 2004). Briefly, spinal cords were manually dissected from chicken embryos at E4.5. Spinal cords were isolated from surrounding tissues and opened along the dorsal midline. The cervico-brachial region was isolated, and this explant was flattened on a nitrocellulose membrane (Sartorius) with neural progenitors up and further grown in DMEM (Invitrogen) supplemented with $10 \%$ FCS (Sigma). For Sulf1-neutralizing experiments, the antiserum $(\alpha$ Sulf1) was added to culture medium at 1:100 and 1:50 dilutions, and preimmune serum was used as control (Gill et al., 2010). For BrdU staining, spinal cord explants were incubated for $2 \mathrm{~h}$ with BrdU $(0.15 \mu \mathrm{g} / \mu \mathrm{l}$; Sigma-Aldrich), 24, 32, or $48 \mathrm{~h}$ after plating. Tissues were then fixed for $4 \mathrm{~h}$ and processed for BrdU immunostaining.

\section{Electroporation}

E4.5 spinal cord electroporation was performed ex ovo. Chicken embryos were harvested and isolated in a Petri dish with the dorsal side up, and DNA solution was injected into the lumen of the spinal cord as described previously (Danesin et al., 2006). Electrodes were positioned on each side of the cervico-brachial region of the spinal cord, the positive electrode being placed more ventrally than the negative one, allowing satisfactory electroporation of ventral regions. Ten pulses of $25 \mathrm{~V}$ were applied, and spinal cord was further dissected and grown in organotypic culture as above. All expression vectors were used at $1 \mu \mathrm{g} / \mu \mathrm{l}$. Expression constructs were cloned into either the PCIG vector (a gift from A. McMahon, Harvard University, Cambridge, MA) for quail Sulf1 (Ai et al., 2003; Danesin et al., 2006) or pRFPRNAiA vector (Das et al., 2006) for sulfiRNAi. The sulf1RNAi vector was constructed according to Das et al. (2006) using a target sequence of 19 nucleotides (5'-AAAACAGAACAGAGUCUUAGAGG$3^{\prime}$ ) designed on chicken sulf1 mRNA using the MWG RNAi Design Tool 
(MWG Biotech). In mutated form of Sulf1 (CC89,90AA), cysteines 89 and 90 have been replaced by alanines to block the $\mathrm{N}$-formylglycine modification, required for catalytic activity but not for substrate binding (Dhoot et al., 2001). Empty pCIG and pRFPRNAiGFP (Das et al., 2006) vectors were used as controls.

\section{Imaging, cell counting, and statistical analyses}

Vibratome tissue slices were analyzed with Leica SP2 and SP5 confocal microscopes. For analyses of mouse tissues, identical confocal acquisition parameters were applied to sibling wild-type and sulf1 mutant embryos. Mouse embryonic tissue slices were harvested from the level of the anterior limb bud. In Olig2 and Sox10 immunostaining experiments, positive cells were considered to belong to the mantle zone when their nuclei were clearly individualized from the Olig2-positive cells of the progenitor zone (Fig. 1). Cell counting was performed on at least five tissue slices per embryo or chicken explant. For each tissue slice (60-80 $\mu \mathrm{m})$, at least four optical sections were acquired at $6 \mu \mathrm{m}$ intervals, and cells were counted in each optical section. The data provided are the average of at least three embryos or explants $(n)$ per condition from at least two independent experiments. Quantifications are expressed as the mean \pm SEM number of cells in an optical section of an hemi-spinal cord or of an hemi-explant. Statistical analyses were performed using the Mann-Whitney $U$ test. Significance was determined at $p<0.05$. $p$ values are indicated in figure legends or in text when quantifications are not included in figures.

\section{Results \\ OPC development is impaired in sulf1-deficient mouse embryonic ventral spinal cord}

In chicken, Sulf1, initially expressed in floor plate cells at stages of neuronal generation, is further upregulated in the ventralmost neural progenitors of the spinal cord immediately before OPC specification, i.e., from E4.5/5 (Braquart-Varnier et al., 2004; Danesin et al., 2006). We first asked whether a similar upregulation of sulf1 also occurs in mice and whether it correlates with the MN-to-OPC switch, known to occur between E11.5 and E12.5 (Richardson et al., 2000). At E10.5, during MN generation, sulf1 expression was restricted to floor plate cells (Fig. $1 A$ ). Its expression domain then extended dorsally, and, from E11.5, sulf1 mRNA was also detected in ventral neural progenitors, adjacent to the floor plate (Fig. 1B,C), indicating that the spatiotemporal course of sulf1 expression defined in chicken is conserved in the mouse. We then turned to a sulf1 knocked out $\left(\right.$ sulf1 $\left.1^{-1-}\right)$ mouse line to directly address the role of sulf1 in OPC development. Mice deficient for Sulf1 show no overt phenotype and are viable and fertile, indicating that the enzyme is not essential for embryonic development (Lamanna et al., 2006; Ai et al., 2007). Only subtle defects in neurite outgrowth have been reported in the developing CNS (Kalus et al., 2009). Despite the lack of drastic phenotype, we postulated that this did not preclude defects in OPC development from ventral spinal cord progenitors. Indeed, in both brain and spinal cord, failure in OPC generation from a single source can be compensated by overproduction of OPCs from other sources (Cai et al., 2005; Vallstedt et al., 2005; Kessaris et al., 2006). We analyzed ventral OPC generation in sulf1deficient embryos using Olig2, a reliable marker of OPCs within the mantle and marginal zones of the developing spinal cord. Indeed, in contrast to MNs, OPCs maintain Olig2 expression when they emigrate from the progenitor zone to reach their final destination (Lu et al., 2000; Takebayashi et al., 2000; Zhou et al., 2000). At E12.5, soon after initiation of OPC generation, we detected Olig2-positive cells dispersed in the mantle zone of wildtype animals (Fig. $1 D$ ). In contrast, only few Olig2-positive cells were observed in the mantle zone of age-matched sulf1-deficient embryos (Fig. 1E). Cell counting revealed a $75 \%$ reduction in
OPC number with an average of $3.02 \pm 0.89$ cells per hemisection in sulf1 $1^{-/}$spinal cords $(n=5)$ compared with $12.48 \pm 1.43$ in wild-type siblings $(n=9$; Fig. $1 H$ ). Such a decrease, although less pronounced than in homozygous mutants, was also observed in sulf1 heterozygous embryos ( $6.66 \pm 1.28$ cells, $n=6$; Fig. $1 H$ and data not shown), suggesting a dosage-dependent regulation of ventral OPC development by sulf1. We did not observe differences in size and shape of the embryonic spinal cord between wild-type and sulf1 $1^{-1-}$ sibling embryos, arguing against the possibility that the defect in OPC generation could simply reflect a delay in development of the CNS in sulf1 mutant embryos. Importantly, the number of Olig2-positive cells in the progenitor zone appeared similar between wild-type and sulf1 mutant embryos (Fig. $1 F, G$ ). Cell counting confirmed that the number of Olig2-expressing cells in the progenitor zone was not affected in E12.5 sulf1-deficient embryos ( $43 \pm 1.52$ in sulf1 mutant, $n=3$, vs $43.3 \pm 1.27$ in wild-type embryos, $n=4$; Fig. $1 H$ ), indicating that Sulf1 is dispensable for formation of the pMN domain and/or maintenance of Olig2 progenitors. However, in our experiments, we noticed differential intensities of the Olig2 signal in the progenitor zone of E12.5 sulf1 $1^{-1}$ embryos that appeared lowered compared with wild types (Fig. 1, compare $F, G$ ).

The reduction in the number of migrating OPCs in sulf1 ${ }^{-/-}$ embryos was still apparent at least until E14.5/E15 (Fig. 1I,J). Quantification of Olig2-expressing cells in the mantle and marginal zones revealed that the number of OPCs was reduced to $60 \%$ of the number counted in age-matched wild-type spinal cords ( $125 \pm 20.9$ cells in sulf1 mutant, $n=4$, vs $204.5 \pm 0.28$ in wild-type embryos, $n=4$; Fig. $1 M$ ). The distribution of Olig2expressing cells in sulf1 $1^{-1-}$ spinal cords, scattered throughout the dorsal and ventral mantle and marginal zones, was similar to that found in wild-type embryos, indicating absence of gross defects in migratory properties of OPCs generated in sulf1 mutant embryos (Fig. 1I,J). Interestingly, in E14.5/E15 sulf1 ${ }^{-/}$spinal cords, contrasting with data obtained at earlier embryonic stages, we observed a reduction in the number of Olig2-expressing cells within the progenitor zone ( $9 \pm 0.61$ cells in sulf1 mutant, $n=4$, vs $15.75 \pm 0.14$ in wild-type embryos, $n=4$; Fig. $1 K-M$ ), indicating that sulf1 loss of function led to a depletion in the pool of Olig2 progenitors at these later stages. Expectedly, around birth, it was no longer possible to distinguish wild-type and sulf $1 \mathrm{mu}-$ tant spinal cords using Olig2 and proteolipid protein (PLP)/ DM20 as oligodendroglial markers (Fig. $1 N-Q$ ), suggesting that dorsal progenitors and/or proliferation/survival of the fewer ventrally generated OPCs might have contributed to replenish the pool of oligodendroglial cells.

Together, our results showing that the OPC number was markedly reduced in E12.5 sulf1 ${ }^{-/-}$embryos, a depletion still apparent $2 \mathrm{~d}$ after the timing of the MN-to-OPC fate switch, clearly point to a role for sulf 1 in the control of ventral OPC generation.

\section{Sulf1 is required for efficient OPC specification from Olig2 progenitors}

We next asked whether the deficient OPC generation in sulf1 mutant embryos resulted from a failure in the initial commitment of Olig2 progenitors toward the OPC fate. To address this question, we used Sox10, the earliest known transcription factor expressed in oligodendrocyte lineage cells of the mouse spinal cord (Kuhlbrodt et al., 1998; Zhou et al., 2000; Stolt et al., 2002). Sox10 is specifically upregulated in Olig2 progenitors fated to generate OPCs as soon as E11.5, and its expression is further maintained in OPCs migrating in the mantle zone (Zhou et al., 


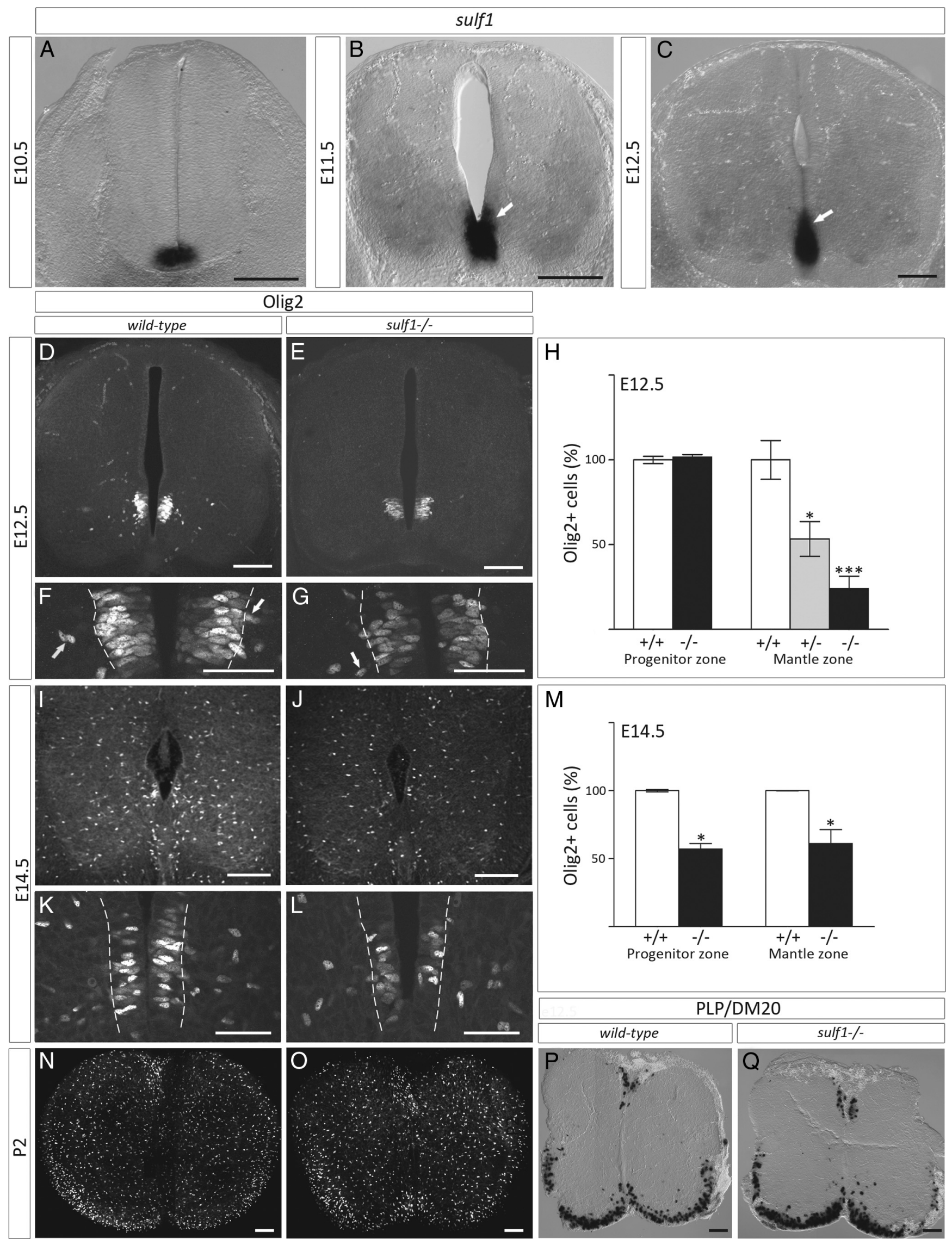

Figure 1. Sulf1 loss-of-function impairs OPC generation from 0lig2 progenitors in the mouse embryonic spinal cord. $A-C$, Temporal expression profile of sulf1 on transverse sections of mouse embryonic brachial spinal cord at E10.5 (A), E11.5 (B), and E12.5 (C). Note the dorsal extension of the sulf1-expressing domain from E11.5 (arrows in $\boldsymbol{B}, \boldsymbol{C}$ ). D- $\mathbf{0}$, (Figure legend continues.) 
2000). Confirming the phenotype observed using Olig2, the number of Sox10-positive cells dispersed in the mantle zone at E12.5 was reduced by $78 \%$ in sulf1 $1^{-1-}$ embryos $(2.55 \pm 0.91, n=$ $5)$ compared with wild-type littermates (11.42 $\pm 1.71, n=5$; Fig. $2 F$ and data not shown). We then focused on Sox 10 expression in the progenitor zone. At E11.5, there was a strong reduction in the number of Sox10-positive cells within the Olig2 progenitor domain of sulf1 $1^{-/-}$embryos $(0.56 \pm 0.16, n=4)$ compared with wild-type littermates ( $3.94 \pm 0.73, n=4$; Fig. $2 A-C$ ). At E12.5, Sox 10 expression was detected in almost $50 \%$ of Olig 2 progenitors in wild-type embryos $(20.48 \pm 1.49, n=5)$, whereas $<20 \%$ of them upregulated Sox10 in sulf1 mutant embryos $(8.11 \pm 1.01$, $n=5$; Fig. $2 D-F$ ). Moreover, as observed previously for Olig2, Sox10 signal intensity in Olig2 progenitors of sulf $1^{-/-}$embryos appeared weaker compared with wild-types at all stages examined (Fig. 2, compare $D, E$ ). High expression levels of these proteins in Olig2 progenitors being required to give them an OPC identity (Stolt et al., 2004; Liu et al., 2007), our results suggest that lowered Olig2/Sox10 expression might contribute to the phenotype observed in sulf1 mutant embryos.

The marked reduction in the number of Olig2 progenitors that upregulate Sox 10 in sulf1 $1^{-/-}$embryos is consistent with Sulf1 acting by promoting OPC specification in the $\mathrm{pMN}$ domain.

\section{Sulf1 controls the MN-to-OPC fate switch of Olig2 progenitors}

Because progenitors of the $\mathrm{pMN}$ domain generate $\mathrm{MNs}$ before switching to the OPC fate, we next examined the consequences of Sulf1 inactivation on MN generation. At E12.5, immunostaining of Islet1 allowed detecting MNs in the ventral horns of the spinal cord, with no discernible difference between wild-type and sulf $1^{-/-}$embryos, indicating no gross defect in MN generation in sulf1 mutants (Fig. $3 A, B$ ). However, we observed that, in sulf1 $1^{-/-}$ embryos, numerous Islet1-positive cells remained in a more medial region, close to the Olig2 progenitor domain compared with wild-type siblings, suggesting that $\mathrm{MNs}$ recently generated were overrepresented in sulf1 mutant embryos. To define whether MN production was indeed prolonged in sulf1 ${ }^{-/}$embryos, we first used ebf2 and ngn2 stainings to identify young neurons in the spinal cord, because their transitory expression in newly specified neurons is a reliable indicator of neuronal generation (Garel et al., 1997; Dubois et al., 1998; Scardigli et al., 2001; Danesin et al., 2006). At E12.5, detection of ebf2 mRNA showed high level of

$\leftarrow$

(Figure legend continued.) Immunodetection of 0lig2 on transverse sections of $\mathrm{E} 12.5(\boldsymbol{D}-\boldsymbol{G})$, E14.5 (I- $\boldsymbol{L})$, and P2 $(\boldsymbol{N}, \boldsymbol{O})$ spinal cords of wild-type $(\boldsymbol{D}, \boldsymbol{F}, \boldsymbol{I}, \boldsymbol{K}, \boldsymbol{N})$ and sulf1 ${ }^{-/-}(\boldsymbol{E}, \boldsymbol{G}, \boldsymbol{J}, \boldsymbol{L}, \mathbf{0})$ embryos. $\boldsymbol{D}, \boldsymbol{E}$, Only few Olig2-positive cells emigrate in the mantle zone of E12.5 sulf1 mutant embryos $(\boldsymbol{E})$ compared with wild-type littermates $(\boldsymbol{D}) . \boldsymbol{F}, \boldsymbol{G}$, Higher magnification of E12.5 spinal cord sections in which the progenitor zone is delineated by dashed lines. Arrows indicate 0lig2positive cells having emigrated in the mantle zone. $\boldsymbol{H}$, Quantification of Olig2-expressing cells in progenitor and mantle zones of E12.5 wild-type $(+/+)$, sulf1 heterozygous $(+/-)$, and sulf1 mutant (-/-) embryos. I, J, At E14.5, the reduction in the number of migrating OPCs was still apparent. $\boldsymbol{K}, \boldsymbol{L}$, Higher magnification of E14.5 spinal cord sections in which the progenitor zone is delineated by dashed lines. Note that the number of Olig2-positive cells in the progenitor zone is reduced in sulf1 mutant embryos ( $\boldsymbol{L}$ ) compared with wild-type littermates $(\boldsymbol{K})$. $\boldsymbol{M}$, Quantification of Olig2-positive cells in progenitor and mantle zones of E14.5 wild-type $(+/+)$ and sulf1 mutant (-/-) embryos. $\mathbf{N}, \mathbf{O}$, At P2, Olig2-expressing cells populate the entire spinal cord and are present in similar densities in wild-type $(\boldsymbol{N})$ and sulf1 mutant ( $(\boldsymbol{O})$ embryos. $\boldsymbol{P}, \mathbf{Q}, \mathbf{P 2}$ spinal cord sections from wild-type $(\boldsymbol{P})$ and sulf1 mutant $(\boldsymbol{Q})$ embryos stained with the PLP/ DM20 probe. In $\boldsymbol{H}$ and $\boldsymbol{M}$, cell numbers obtained for wild-type embryos were arbitrarily set to 100\%. All other values were expressed relative to wild-type levels and are presented as mean \pm SEM. Statistical significance is indicated above the respective bars $\left({ }^{*} p \leq 0.02 ;{ }^{* * *} p \leq 0.001\right)$. Scale bars: $\mathbf{A}-\boldsymbol{E}, \boldsymbol{I}, \boldsymbol{J}, \mathbf{N}-\mathbf{Q}, 100 \mu \mathrm{m} ; \boldsymbol{F}, \mathbf{G}, \boldsymbol{K}, \boldsymbol{L}, 50 \mu \mathrm{m}$. expression in cells adjacent to dorsal progenitors of the spinal cord, whereas only faint expression was detected in cells facing the Olig2-expressing domain, in agreement with the fact that MNs were no longer produced at this stage (Fig. $3 C$ ). In contrast, in E12.5 sulf1 mutant embryos, a higher level of ebf2 expression was detected at the level of the pMN domain, indicating that MN genesis was still occurring at this late stage (Fig. 3D). Similarly, although the proneural gene ngn2 was not detected at the level of the pMN domain in wild-type embryos, cells emerging from this domain were detected in littermate sulf1 mutant embryos (Fig. $3 E, F)$, again supporting ongoing generation of neurons at a stage when Olig2 progenitors have normally switched to OPC production. Because OPCs, even reduced in number, were generated from E11.5 in sulf1 mutant embryos (Fig. 2), these results suggested that Olig2 progenitors might simultaneously generate MNs and OPCs in sulf1-deficient embryos. According to the MN/ OPC switch model, this situation should never be observed in wild-type conditions. To further investigate this point, we examined MN generation at the cellular level. For this, we analyzed Olig2 and Islet 1 coexpression at various developmental stages in wild-type embryos and compared these patterns with the profile obtained in E12.5 sulf1 mutant embryos. At E10.5 in wild-type embryos, we detected Olig2/Islet1-coexpressing cells leaving the progenitor zone, corresponding to newly generated MNs that upregulated Islet1 before switching off Olig2 (Fig. 4A). At E11.5, few Islet1-expressing cells were still detected in the medial region of the spinal cord, close to the Olig2 progenitor domain, but they no longer coexpressed Olig2, reflecting their more mature state (Fig. 4B). Moreover, at this stage, we detected few Olig2-positive/ Islet1-negative cells that had already left the progenitor zone, as well as Sox10-expressing cells in the progenitor zone (Fig. 4B,C), indicating initiation of OPC generation. At E12.5, in agreement with the previously reported cessation of $\mathrm{MN}$ generation at this stage (Stolt et al., 2003), none of the few Islet1-positive cells remaining in close vicinity to the pMN domain coexpressed Olig2 in wild-type embryos (Fig. $4 E$ ). These data reinforce the model of the $\mathrm{MN}$-to-OPC fate switch in mouse occurring in a narrow time window during spinal cord development. In contrast, double Olig2/Islet1-positive young MNs were invariably detected in contact with the pMN domain until at least E12.5 in sulf1 mutant embryos (Fig. $4 F$ ), confirming that $\mathrm{MN}$ production was prolonged in this context, whereas few OPCs have already been specified (Fig. 4D). Therefore, in sulf1 mutant embryos, MNs and OPCs were simultaneously generated, a situation never encountered in wild-type embryos. This result is an additional argument against the possibility that the phenotype we observed in sulf1 mutant embryos might simply result from a general delay in cell fate change of Olig2 progenitors.

Together, our results show that sulf1 ${ }^{-/-}$mutants display a partial and very specific failure of Olig2 progenitors to turn off the MN program and switch on OPC production, resulting in a situation in which pMN progenitors concomitantly generate MNs and OPCs. This phenotype agrees with Sulf1 being involved in favoring the recruitment of Olig2 neural progenitors to generate OPCs instead of MNs.

\section{Sulf1 activity is precisely required at the time of the MN-to- OPC fate switch to trigger Olig2 progenitor cell fate change} The MN-to-OPC fate switch defect in sulf1-deficient mice raised the question of the temporal window of Sulf1 activity in controlling the fate of Olig2 progenitors. Sulf1 expression pattern changes with time, and a novel source of the enzyme forms in ventral neural progenitors before the MN-to-OPC fate switch in 


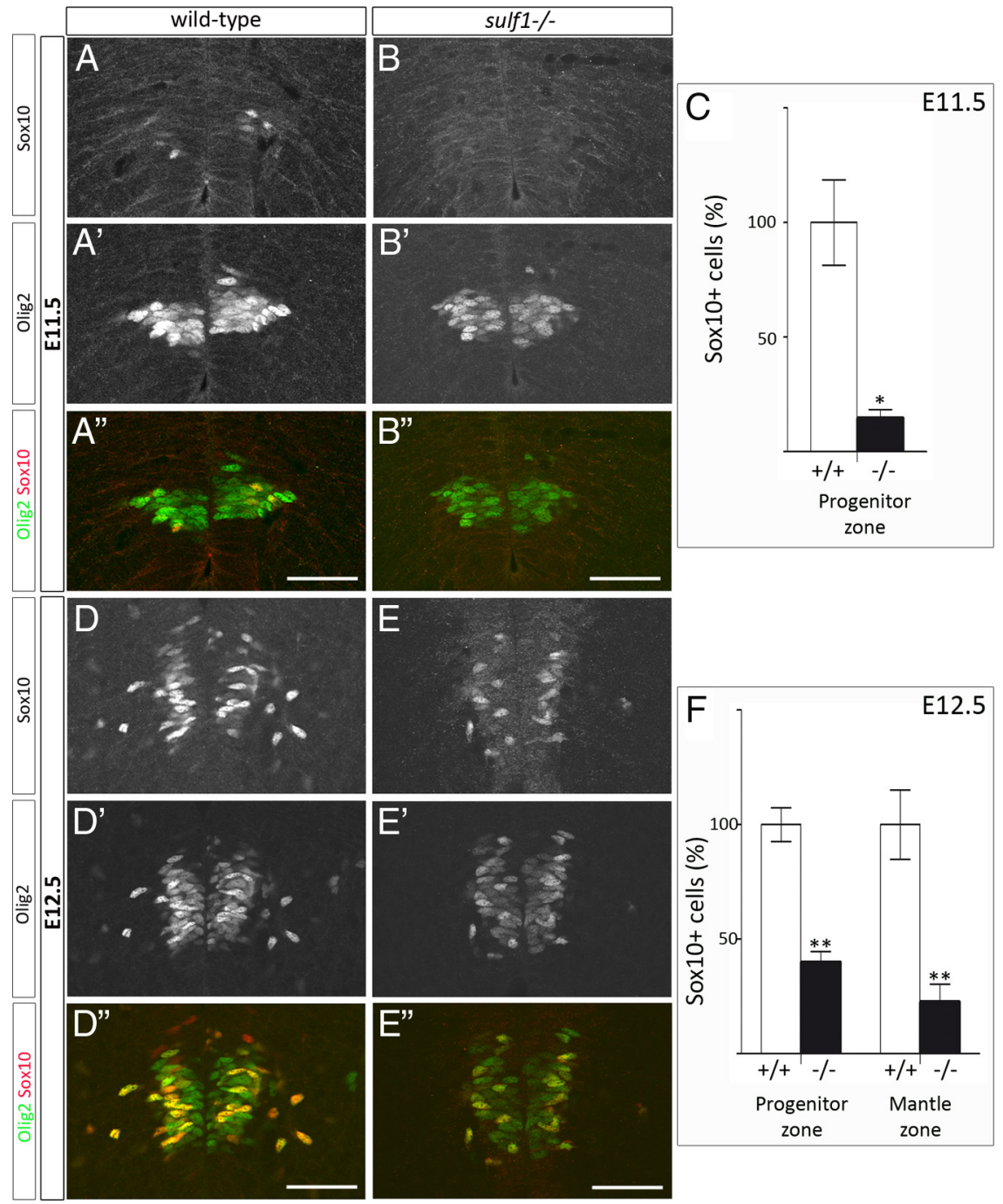

Figure 2. Sulf1 loss-of-function results in defective OPC specification from 0lig2 progenitors. Double immunodetection of Sox10 and Olig2 in $\mathrm{E} 11.5(\boldsymbol{A}, \boldsymbol{B})$ and $\mathrm{E} 12.5(\boldsymbol{D}, \boldsymbol{E})$ wild-type $(\boldsymbol{A}, \boldsymbol{D})$ and sulf1 mutant $(\boldsymbol{B}, \boldsymbol{E})$ embryos. Images show high magnifications of the progenitor zone, and each vertical set presents successively Sox10 staining, 0lig2 staining, and the merged image (Sox10 in red and 0lig2 in green). Note the reduction in the number of Olig2 and Sox10-coexpressing cells, as well as low Olig2 and Sox10 signal intensities in the few OPCS detected in the progenitor zone of E12.5 sulf1 mutant embryos compared with wild-type littermates. C, Quantification of Sox 10-expressing cells in the progenitor zone of E11.5 wild-type $(+/+)$ and sulf1 mutant $(-/-)$ embryos. $F$, Quantification of Sox10-expressing cells in the progenitor zone and in the mantle zone of E12.5 wild-type $(+/+)$ and sulf 1 mutant $(-/-)$ embryos. In $C$ and $\boldsymbol{F}$, cell numbers obtained for wild-type embryos were arbitrarily set to $100 \%$. All other values were expressed relative to wild-type levels and are presented as mean \pm SEM. Statistical significance is indicated above the respective bars $\left({ }^{*} p \leq 0.02 ;{ }^{* *} p \leq 0.01\right)$. Scale bars, $50 \mu \mathrm{m}$.

both mouse and chicken (Fig. 1; Braquart-Varnier et al., 2004). This raises the question of the relevance of this temporal change in Sulf1 expression pattern for proper OPC specification. To address this question, we took advantage of the chicken model, which allows interfering with gene function at late developmental stages in explant cultures of embryonic spinal cord (Agius et al., 2004, 2010; Danesin et al., 2006). Chicken spinal cord explants were isolated at E4.5, i.e., just before OPC specification, which occurs between E5 and E5.5 (Soula et al., 2001). This stage also corresponds to initiation of Sulf1 expression in ventral neural progenitors in chicken (Braquart-Varnier et al., 2004). With this system, the temporal fate of neural progenitors is maintained and OPC migration in the mantle zone can be readily observed after $2 \mathrm{~d}$ in culture, a stage equivalent to E6.5 (Agius et al., 2004; Danesin et al., 2006) (Fig. 5A). As a first step in the use of this ex vivo experimental model to study Sulf1 function, we adapted an RNA interference system described previously (Das et al., 2006). A sulf1RNAi vector was constructed and electroporated into ventral neural progenitors at the time of plating (E4.5). We first established its efficacy in downregulating Sulf1 expression using immunodetection and ISH after $2 \mathrm{~d}$ in culture. Electroporation of the sulf1RNAi vector efficiently silenced Sulf1 expression at both protein and mRNA levels, whereas the use of a control vector ( $g f p$ RNAi vector) had no effect (Fig. 5B, C and data not shown). We then examined the consequences of late inactivation of Sulf1 on OPC development. After $2 \mathrm{~d}$ in culture, electroporation of the sulf1RNAi vector led to a greater than twofold reduction in the number of Olig2-positive migrating OPCs in the mantle zone of the electroporated side (3.6 $\pm 0.33, n=5$ ) compared with the non-electroporated side of the explants (8.14 $\pm 2.5, n=5$; Fig. $5 F, G)$, whereas electroporation of the control $g f$ $p$ RNAi vector did not significantly affect this number $(9.9 \pm 0.69, n=4)$ compared with the non-electroporated side of the explants $(11,43 \pm 0.4, n=4$; Fig. $5 E, G)$ or non-electroporated explants (11.55 \pm 1.38 and $11.78 \pm 0.65$ on either side of explants, $n=5$; Fig. $5 A, G$ ). To confirm these data, we used two distinct approaches reported previously to successfully impair Sulf1 function: overexpression of a dominant-negative form of Sulf1 (Sulf1 ${ }^{\mathrm{DN}}$; Dhoot et al., 2001) or treatment with a Sulf1 blocking antibody ( $\alpha$ Sulf1; Gill et al., 2010). Similar results were obtained with both methods. Sulf1 ${ }^{\text {DN }}$ overexpression caused a $50 \%$ reduction in the number of Olig2expressing cells in the mantle zone compared with the non-electroporated side of the explants $(4.2 \pm 1.88$ vs $9 \pm 1.50$ cells, $n=4$; Fig. $5 \mathrm{~J}, \mathrm{~K})$. Furthermore, treatment with the $\alpha$ Sulf1 blocking antibody resulted in a dose-dependent inhibition of OPC generation (Fig. $5 L-N$ ), with a 60 and $80 \%$ reduction in OPCs after incubation in 1:100 ( $4 \pm 0.37, n=10)$ and 1:50 $(2.45 \pm 0.66, n=$ 4) dilution of the $\alpha$ Sulf1 serum, respectively, compared with control experiments performed with preimmune serum $(11.17 \pm 1.8, n=3)$. These data showed that Sulf1 activity is required at the time of the $\mathrm{MN}$-to-OPC fate switch for proper OPC generation.

Noticeably, in sulf1RNAi experiments mentioned above, knockdown of sulf1 targeted to ventral neural progenitors but also to floor plate cells did not modify the number of OPCs in the non-electroporated side of explants compared with control conditions (Fig. 5F). This observation suggested that Sulf1 function for OPC generation could be fulfilled by ventral neural progenitors but not by floor plate cells. We therefore examined spinal cord explants in which electroporation of the sulf1RNAi vector was mainly targeted to ventral medial cells and observed that the number of migrating OPCs on either side of the spinal cord ex- 


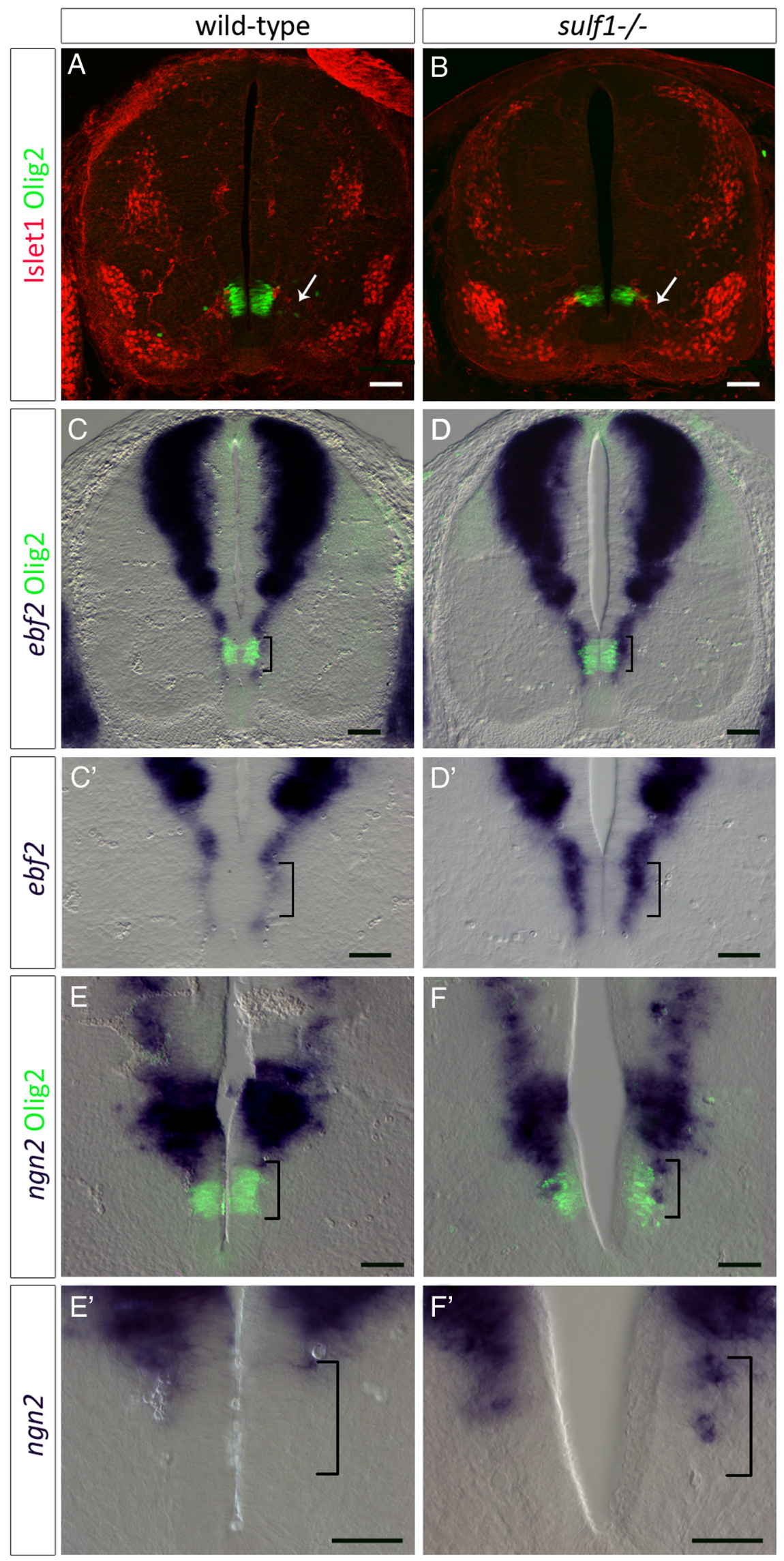

Figure 3. Generation of neurons is prolonged after the normal timing of the MN-to-OPC fate switch in sulf1-deficient mouse embryos. $\boldsymbol{A}, \boldsymbol{B}$, Double immunodetection of Islet1 (red) and 0lig2 (green) on transverse sections of E12.5 wild-type $(\boldsymbol{A})$ and plant was not modified compared with non-electroporated control explants (Fig. $5 H, I)$, confirming that expression of Sulf1 in floor plate cells is dispensable for OPC generation.

To assess whether sulf1 knockdown in chicken also affects OPC specification, we performed double staining of Olig2 and Nkx2.2, their coexpression in neural progenitors being a well-established hallmark of OPC specification in chicken (Zhou et al., 2001). Impairment of Sulf1 function using the $\alpha$ Sulf1 blocking antibody led to a reduction of $60 \%$ in the number of Nkx2.2/Olig2-coexpressing cells in the progenitor zone $(2.9 \pm 0.22$ cells, $n=4$, $p<0.0001)$ compared with control explants incubated with the preimmune serum (7.53 $\pm 0.44, n=3$; Fig. $6 A, B)$. These results indicated that Sulf1 is required for upregulation of $\mathrm{Nkx} 2.2$ expression in Olig2 progenitors to trigger their cell fate switch. In addition, we observed a clear defect in the dorsal extension of the Nkx2.2-positive/Olig2-negative p3 domain after Sulf1 inactivation (Fig. $6 A^{\prime}, B^{\prime}$ ), a fact very reminiscent of Shh signaling inhibition (see below). We then assessed MN production using the specific marker MNR2 in spinal cord explants either treated with the $\alpha$ Sulf1 blocking antibody or electroporated with the sulfiRNAi vector. We observed an increase in $\mathrm{MN}$ density close to the progenitor zone in explants incubated with the $\alpha$ Sulf1 antibody compared with control explants incubated with the preimmune serum (Fig. $6 C, D)$. Similarly, after electroporation of the sulf1RNAi vector, MNR2-positive cells in immediate vicinity of the progenitor zone were overrepresented in the electroporated side of explants compared with the nonelectroporated side (Fig. 6G). These results suggested that inactivation of Sulf1 at stage of the MN-to-OPC fate switch leads to pro-

sulf1 mutant $(\boldsymbol{B})$ embryos. Note the detection of Islet1expressing cells close to the 0lig2 progenitor domain in E12.5 sulf1 mutant embryos ( $\boldsymbol{B}$, arrow), whereas only few of them were found in wild-type littermates $(\boldsymbol{A}$, arrow). $\boldsymbol{C}-\boldsymbol{F}$, Double labeling of E12.5 spinal cord sections using ISH for ebf2 $(\boldsymbol{C}, \boldsymbol{D})$ or $n g n 2(\boldsymbol{E}, \boldsymbol{F})$ probes and immunodetection for Olig2 (green), performed on wild-type $(\boldsymbol{C}, \boldsymbol{E})$ and sulf1 mutant $(\boldsymbol{D}, \boldsymbol{F})$ embryos. In $\boldsymbol{C}, \boldsymbol{D}, \boldsymbol{E}$, and $\boldsymbol{F}$, a confocal image of 0lig2 staining (green) was overlaid with the bright-field image of the same section to allow precise positioning of the pMN domain relative to cells expressing ebf2 $(\boldsymbol{C}, \boldsymbol{D})$ and $n g n 2(\boldsymbol{E}, \boldsymbol{F})$. Expression profiles of ebf2 and ngn2 appeared quite similar between wild-type and sulf1 mutant embryos except at the level of the pMN domain (delineated with brackets), in which a higher level of ebf2 expression (compare $\boldsymbol{C}^{\prime}$ with $\boldsymbol{D}^{\prime}$ ) and ngn2positive cells (compare $\boldsymbol{E}^{\prime}$ with $\boldsymbol{F}^{\prime}$ ) were detected in sulf1 mutant embryos. Scale bars, $50 \mu \mathrm{m}$. 

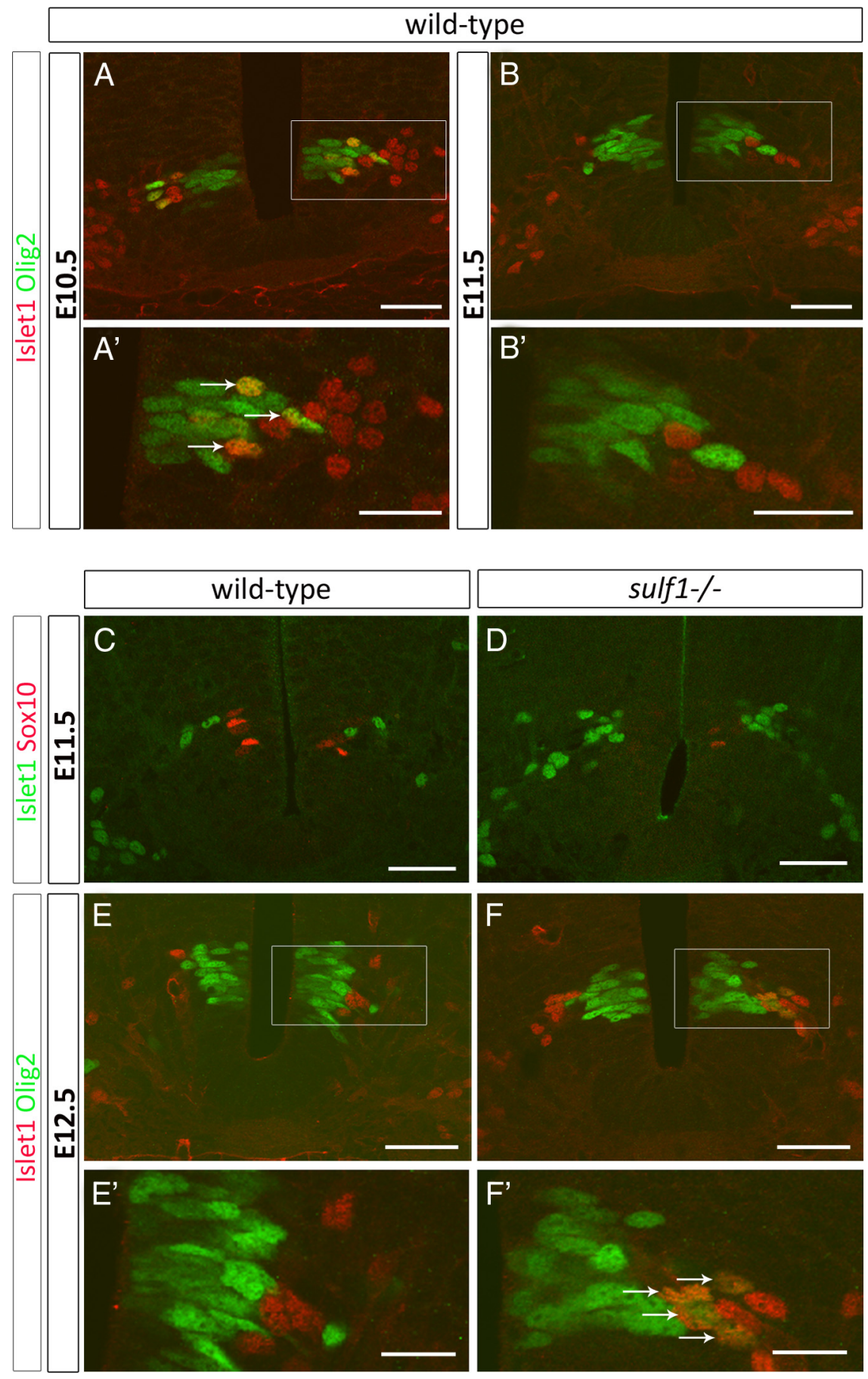

Figure4. MNs and OPCsare simultaneously generated in E12.5 sulf1 mutantembryos. $A, B$, Time course of Islet1 (red) and Olig2 (green) expression in E10.5 $(\boldsymbol{A})$ and E11.5 $(\boldsymbol{B})$ wild-type embryos. $\boldsymbol{A}^{\prime}, \boldsymbol{B}^{\prime}$, Higher magnifications of the areas framed in $\boldsymbol{A}$ and $\boldsymbol{B}$, showing newly generated MNs marked by the coexpression of both transcription factors at E10.5 (arrows in $\boldsymbol{A}^{\prime}$ ) but not at E11.5 $\left(\boldsymbol{B}^{\prime}\right)$. $\boldsymbol{C}-\boldsymbol{F}$, Comparison of Islet 1, Sox10, and 0lig2 expression in wild-type $(\boldsymbol{C}, \boldsymbol{E})$ and sulf1 mutant $(\boldsymbol{D}, \boldsymbol{F})$ embryos. $\boldsymbol{C}, \boldsymbol{D}$, Double immunodetection of Islet1 (green) and Sox10 (red) in E11.5 wild-type $(\boldsymbol{C}$ ) and sulf1 mutant (D) embryos showing higher density of Islet1-expressing cells close to the progenitor zone in sulf1 mutant embryos. Note the presence of few Sox10-positive OPCs already detected at this stage in sulf1 mutant spinal cord. $\boldsymbol{E}, \boldsymbol{F}$, Double staining of Islet1 (red) and Olig2 (green) performed on wild-type $(\boldsymbol{E})$ and sulf1 mutant $(\boldsymbol{F})$ E12.5 spinal cords. $\boldsymbol{E}^{\prime}, \boldsymbol{F}^{\prime}$, Higher magnifications of the areas framed in $\boldsymbol{E}$ and $\boldsymbol{F}$ showing that cells coexpressing 0lig2 and Islet1 (arrows in $\boldsymbol{F}^{\prime}$ ) were detected in sulf1 mutant embryos but not in wild-type littermates $\left(\boldsymbol{E}^{\prime}\right)$. Scale bars: $\boldsymbol{A}, \boldsymbol{B}, \boldsymbol{C}-\boldsymbol{F}, 50 \mu \mathrm{m} ; \boldsymbol{A}^{\prime}, \boldsymbol{B}^{\prime}, \boldsymbol{E}^{\prime}, \boldsymbol{F}^{\prime}, 20 \mu \mathrm{m}$

longed production of MNs from Olig2 progenitors, as observed in sulf1-deficient mouse embryos. To confirm this, we performed birthdating experiments using BrdU. Two hour BrdU pulses were performed at 24, 32, and $48 \mathrm{~h}$ after plating, equivalent stages to E5.5, E6, and E6.5, respectively (Fig. 6E, F and data not shown). In control conditions, rare BrdU- and MNR2-positive cells were detected in explants incubated with BrdU at $24 \mathrm{~h}(0.21 \pm 0.1, n=3)$, and they were no longer detected when pulses were performed at $32 \mathrm{~h}(n=3)$ and $48 \mathrm{~h}$ $(n=3$; Fig. $6 E)$, in agreement with cessation of MN generation after E5/E5.5 in chicken. In contrast, double-labeled cells were invariably observed in explants treated with the $\alpha$ Sulf1 blocking antibody. Cell counting showed a number of $1.24 \pm 0.2,1.19 \pm 0.1$, and $0.47 \pm 0.1$ double-labeled cells for pulses performed on at least three distinct explants at 24, 32, and $48 \mathrm{~h}$ (Fig. $6 \mathrm{~F}$ and data not shown), respectively, confirming prolonged generation of MNs from actively proliferating cells during the last $24 \mathrm{~h}$ of culture, i.e., until E6.5. These results show that inactivation of Sulf1 just before the MN-toOPC fate switch is sufficient to prevent arrest of MN generation by Olig2 progenitors.

Together, these results confirm and extend data obtained in mouse by showing that Sulf1 activity is required at the time of the MN-to-OPC fate switch to trigger Olig2 progenitor cell fate change.

\section{Sulf1 is a positive regulator of Shh signaling in Olig2 progenitors as they switch to the OPC fate}

Our functional analyses implying Sulf1 in the control of the MN-to-OPC fate switch open the question of the mechanism involved. Hedgehog signaling, given its central role in OPC specification and its functional relationship with Sulf1 both in chicken and Drosophila (Danesin et al., 2006; Wojcinski et al., 2011), was proposed as a prime candidate to be regulated by Sulf1. Our previous data (Danesin et al., 2006), showing that overexpression of Sulf1 in the developing chicken spinal cord is sufficient to upregulate $p t c 1$, the Shh receptor and also an Shh-responsive gene (Goodrich et al., 1996), indicated that Sulf1 behaves as a positive regulator of Shh in this tissue. To further evaluate the role of Sulf1 in controlling the Shh pathway at the MN-to-OPC switch, we first analyzed the expression of Shhresponsive genes after Sulf1 inactivation. As reported previously (Danesin et al., 2006), between E4 and E6 in chicken, ptc1 expression became elevated in two bilateral domains of the ventral progenitor zone (Fig. 7A), indicating increased level of Shh activity in these neural progenitors. Addition of Sulf1 blocking antibody at the time of plating led to inhibition of ptcl expression at this level (Fig. $7 B$ ), indicating that Sulf1 inactivation prevented the rise in Shh signaling normally observed during this time window. In the mouse, whether or not a similar temporal elevation of Shh activity is also responsible for the $\mathrm{MN}$-to-OPC fate switch is unknown. To 


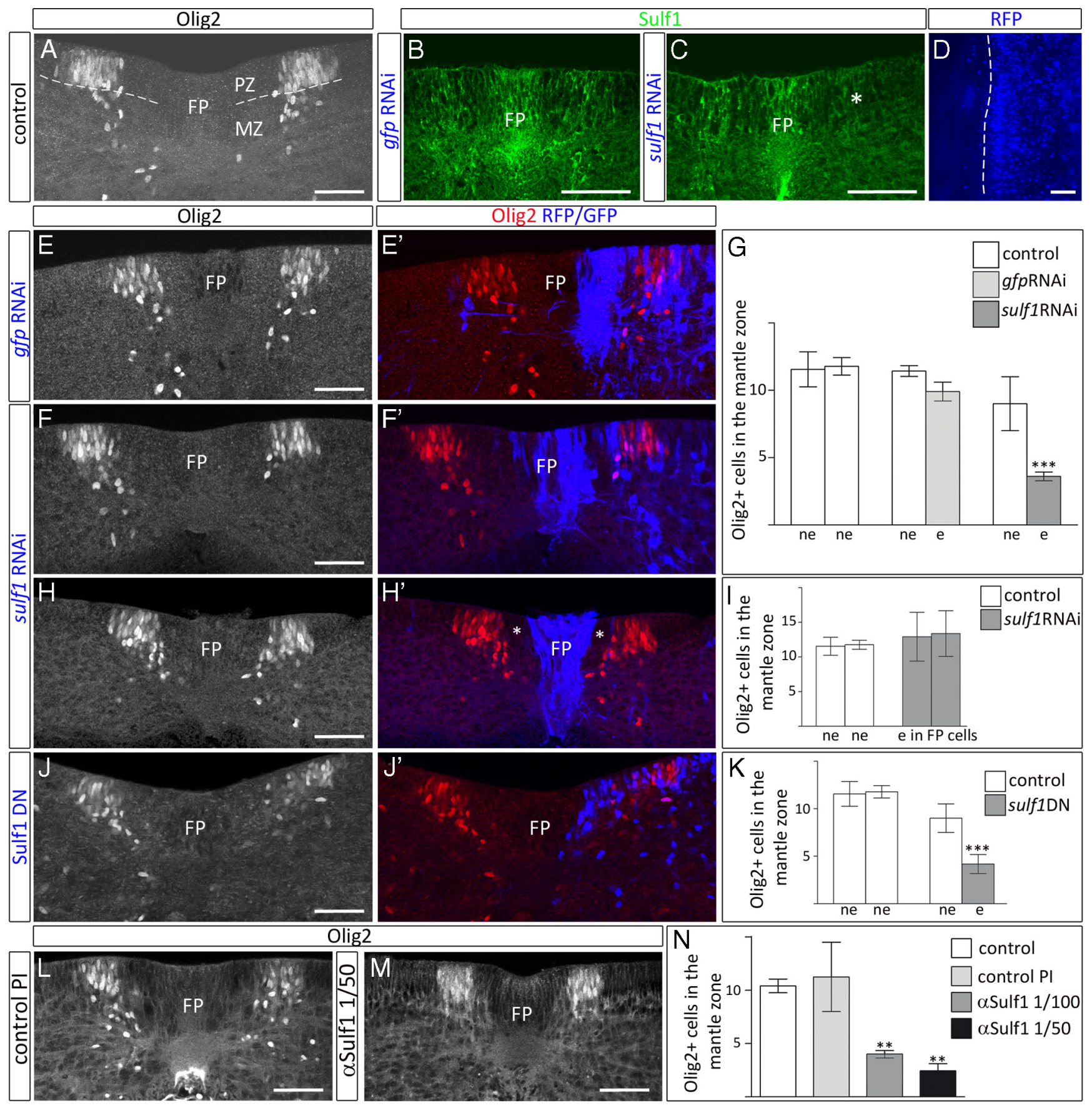

Figure 5. Impairment of Sulf1 function immediately before the MN-to-OPC fate switch is sufficient to inhibit OPC generation in chicken spinal cord. $A$, Immunodetection of Olig2 on a transverse section of chicken spinal cords isolated at E4.5 and cultivated as opened-book explants showing OPCs generated after $2 \mathrm{~d}$ in culture in control conditions. The dashed lines delineate the progenitor zone (PZ) and the mantle zone (MZ). Note detection of OPCs migrating in the mantle zone on each side of spinal cord control explants. B, C, Immunodetection of Sulf1 after electroporation of gfpRNAi control vector (B) and sulfiRNAivector (C). Because the use of ethanol/acetic-acid fixative, required for preservation of Sulf1 immunoreactivity, also leads to extinction of the RFP fluorescent signal, electroporation is monitored before fixation on whole spinal cord explants as exemplified in D (dashed line indicates the midline, RFP signal is in blue). In $\boldsymbol{B}$ and $\boldsymbol{C}$, the electroporated side of explants is on the right. Note detection of Sulf1 in floor plate cells (FP), as well as in bilateral ventral neural progenitors in explants electroporated with gfpRNAi control vector $(\boldsymbol{B})$, whereas electroporation with sulf1RNAi vector inhibits Sulf1 immunoreactivity on the electroporated side of the explants (asterisk in C. $\boldsymbol{E}_{,} \boldsymbol{E}^{\prime}$, Electroporation of the gfpRNAi control vector (blue in $\boldsymbol{E}^{\prime}$ ) does not affect generation of Olig2-positive OPCs (red in $\boldsymbol{E}^{\prime}$ ) on the electroporated side of the explants compared with the non-electroporated contralateral side or to control explants (compare $\boldsymbol{E}$ with $\boldsymbol{A}$ ). $\boldsymbol{F}, \boldsymbol{F}^{\prime}$, Electroporation of the sulfiRNAi vector (blue in $\boldsymbol{F}^{\prime}$ ) in a broad domain covering the ventral progenitor zone inhibits generation of Olig2-positive OPCs in the mantle zone (red in $\boldsymbol{F}^{\prime}$ ) in the electroporated side of the explants compared with the non-electroporated contralateral side or with control explants (compare left side in $\boldsymbol{F}$ and $\boldsymbol{A}$ ). $\boldsymbol{H}, \boldsymbol{H}^{\prime}$, Electroporation of the sulf1RNAi vector (blue in $\boldsymbol{H}^{\prime}$ ) in ventral medial cells but not in neural progenitors adjacent to the Olig2 progenitor domain (asterisks in $\boldsymbol{H}^{\prime}$ ) has no effect on the production of Olig2-positive OPCs (red in $\boldsymbol{H}^{\prime}$ ) compared with non-electroporated control explants (compare $\boldsymbol{H}$ with $\boldsymbol{A}$ ). $\boldsymbol{J}, \boldsymbol{J}^{\prime}$, Electroporation of the Sulf1 ${ }^{\text {DN }}$-expressing vector (blue in $\boldsymbol{J}^{\prime}$ ) inhibits generation of Olig2-positive OPCs (red in $\boldsymbol{J}^{\prime}$ ) on the electroporated side of the explants compared with the non-electroporated side and with control explants (compare $\boldsymbol{J}$ and $\left.\boldsymbol{A}\right)$. $\mathbf{G}, \boldsymbol{I}, \boldsymbol{K}$, Quantification of Olig2-positive cells migrating in the mantle zone on each side of the explants in control condition (control), after electroporation of gfpRNAi control vector $(\mathbf{G})$, sulf1RNAi vector $(\mathbf{G}, \boldsymbol{I})$, and Sulf1 ${ }^{\text {DN }}$-expressing vector $(\boldsymbol{K})$. Results are presented as mean \pm SEM number of cells $\left({ }^{* *} p \leq 0.001\right)$. ne, Non-electroporated side of the explants; e, electroporated side of the explants. $L, M, 0$ lig2 immunolabeling after treatment with the control preimmune serum (control PI, $L$ ) or Sulf1-blocking antibody ( $\alpha$ Sulf1) diluted at 1:50 (M). $N$, Quantification of Olig2-positive cells migrating in the mantle zone of spinal cord explants cultivated in control condition (control), in the presence of the preimmune serum (control PI), or after incubation with $\alpha$ Sulf1 diluted at 1:100 and 1:50. Results are presented as mean \pm SEM number of cells per optical hemisection of spinal cord explants $\left({ }^{* *} p \leq 0.01\right)$. FP, Floor plate. Scale bars, $50 \mu \mathrm{m}$. 

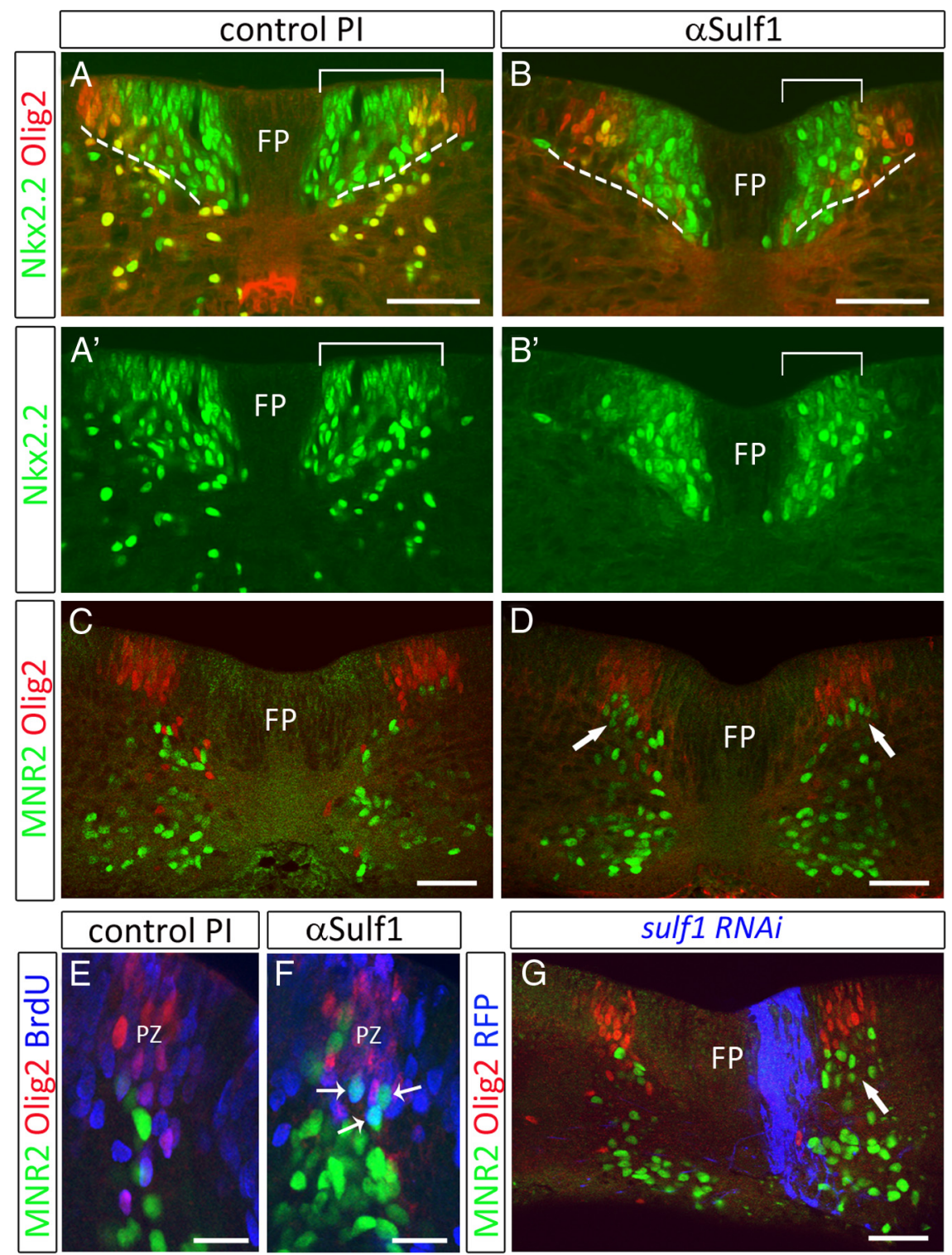

sulf1 RNAi

Figure 6. Impairment of Sulf1 function during the MN-to-OPC fate switch inhibits OPC specification and allows prolonged MN production in chicken spinal cord. $\boldsymbol{A}-\boldsymbol{B}^{\prime}$, Double detection of 0lig2 (red) and Nkx2.2 (green) after treatment with the preimmune serum (control PI, $\boldsymbol{A}$ ) or Sulf1 blocking antibody diluted at 1:50 $(\alpha$ Sulf1, $\boldsymbol{B})$. Treatment with $\alpha$ Sulf1 reduced the number of Olig2/Nkx2.2 double-labeled OPCs in both the mantle zone and the progenitor zone (delineated by dashed line) compared with control explants incubated with the preimmune serum. Note reduction of the dorsoventral extension of the Nkx2.2-expressing domain (brackets in $\left.\boldsymbol{A}^{\prime}, \boldsymbol{B}^{\prime}\right)$ in explants incubated with $\alpha$ Sulf1 $\left(\boldsymbol{B}^{\prime}\right)$ compared with control Pl explants $\left(\boldsymbol{A}^{\prime}\right)$. $\boldsymbol{C}-\boldsymbol{F}$, Detection of Olig2 (red), MNR2 (green), and BrdU (blue in $\boldsymbol{E}, \boldsymbol{F})$ in control PI conditions $(\boldsymbol{C}, \boldsymbol{E})$ or in the presence of $\alpha$ Sulf1 $(\boldsymbol{D}, \boldsymbol{F})$. $\boldsymbol{E}$ and $\boldsymbol{F}$ show higher magnification of the progenitor zone (PZ). Note that MNR2-labeled cells in contact with the Olig2-positive domain are overrepresented in the explants treated with $\alpha$ Sulf1 (arrows in $\boldsymbol{D}$, green in $\boldsymbol{F}$ ) compared with control Pl explants $(\boldsymbol{C}, \boldsymbol{E})$. In $\boldsymbol{E}$ and $\boldsymbol{F}$, a BrdU pulse has been performed at $32 \mathrm{~h}$ after plating. Note the presence of MNR2-positive cells stained with the BrdU antibody in explants treated with $\alpha$ Sulf1 (arrows in $\boldsymbol{F}$ ) but not in control PI explants $(\boldsymbol{E})$. $\mathbf{G}$, Double detection of Olig2 (red) and MNR2 (green) on explants electroporated with the sulf1RNAi vector (blue) showing accumulation of MNR2-positive cells on the electroporated side (arrow) compared with the non-electroporated side. FP, Floor plate. Scale bars: $A-D, G, 50 \mu \mathrm{m} ; E, F, 20 \mu \mathrm{m}$.

evaluate Shh signaling in mouse embryonic spinal cord, we analyzed expression of $p t c l$ and $g l i 1$, the latter being reported to be activated in cells that are exposed to high levels of Shh signaling (Bai et al., 2002; Bai et al., 2004). Double detection of each of these genes together with Olig2 at E12.5 showed both ptc1 and gli1 mRNA expression in the pMN domain (Fig. $7 C, D$ ), indicating that Olig2 progenitors are indeed subjected to Shh activity at this stage. We then compared the expression patterns of $p t c 1$ and gli1 in E12.5 wild-type and sulf1 $1^{-1}$ littermates. Detection of $p t c 1 \mathrm{mRNA}$ in wild-type embryos showed differential levels of expression between the dorsal and ventral parts of the progenitor zone, with the signal being stronger in ventral progenitors (Fig. 7C,E), indicating a higher Shh activity in this region. In contrast, we observed a quite homogeneous signal all along the dorsoventral axis in sulf1 mutant spinal cords (Fig. 7F). A strong expression of gli1 was also observed in the ventral region of wild-type embryos (Fig. $7 D, G$ ). In contrast, in sulf1 mutant littermates, only faint expression of gli1 was detected at this level, whereas the more dorsal expression domains seemed unaffected (Fig. $7 H$ ). These results, in good agreement with a high level of Shh signaling in ventral neural progenitors at the onset of OPC generation in mouse embryos, support a positive regulatory role of Sulf1 in activating Shh signaling at this stage. Importantly, we found that $s h$ expression was not modified in sulf1 mutant embryos compared with wild-type siblings (Fig. $7 I, J$ ), indicating that the influence of Sulf1 on Shh signaling did not depend on transcriptional downregulation of the morphogen factor.

To confirm the functional relationship between Sulf1 and Shh in mouse, we turned to genetic interaction experiments. We postulated that, if the reduction in OPC generation in sulf1 $1^{-/-}$embryos indeed reflected a reduced level of Shh signaling in Olig2 progenitors, then lowering the dosage of shh would be expected to enhance this phenotype. To test this prediction, sulf1;shh compound mutants were analyzed. First, we compared wild-type and $s h h^{+/-}$littermate embryos and found that $\mathrm{shh}^{+/-}$E12.5 embryos were phenotypically normal and displayed a number of Olig2/Sox10coexpressing OPCs in the progenitor zone similar to that of wild-type littermates (22.27 \pm 0.65 in $s h h^{+/-}$embryos, $n=3$, vs $22.26 \pm 1.77$ in wild-type siblings, $n=4$; Fig. $8 A-C)$. Similarly, loss of one shh allele had no effect on OPCs migrating in the mantle zone $\left(22.2 \pm 1.2, n=3\right.$ in shh $h^{+/-}$ embryos vs $23 \pm 1.12$ in wild-type siblings, $n=4$; Fig. $8 \mathrm{C}$ and data not shown). We next compared OPC specification in sulf1 $1^{-/} ;$shh $^{+/-}$and sulf1 $1^{-/-} ;$shh $^{+/+}$ E13.5 littermate embryos. The number of Olig2 and Sox10-coexpressing OPCs in the progenitor zone was significantly reduced in sulf1 $1^{-1-}$; $\operatorname{shh}^{+/-}$embryos (7.59 $\left.\pm 0.04, n=4\right)$ compared with sulf1 ${ }^{-/}$; shh ${ }^{+/+}$littermates $(13.3 \pm 0.52$ cells, $n=4$; Fig. $8 D-F)$, showing a genetic interaction between sulf1 and shh.

Together, our data evidence a role for Sulf1 in controlling Shh signaling at the time of OPC specification in both chicken and mouse, with the enzyme acting as a positive regulator of this signal. 

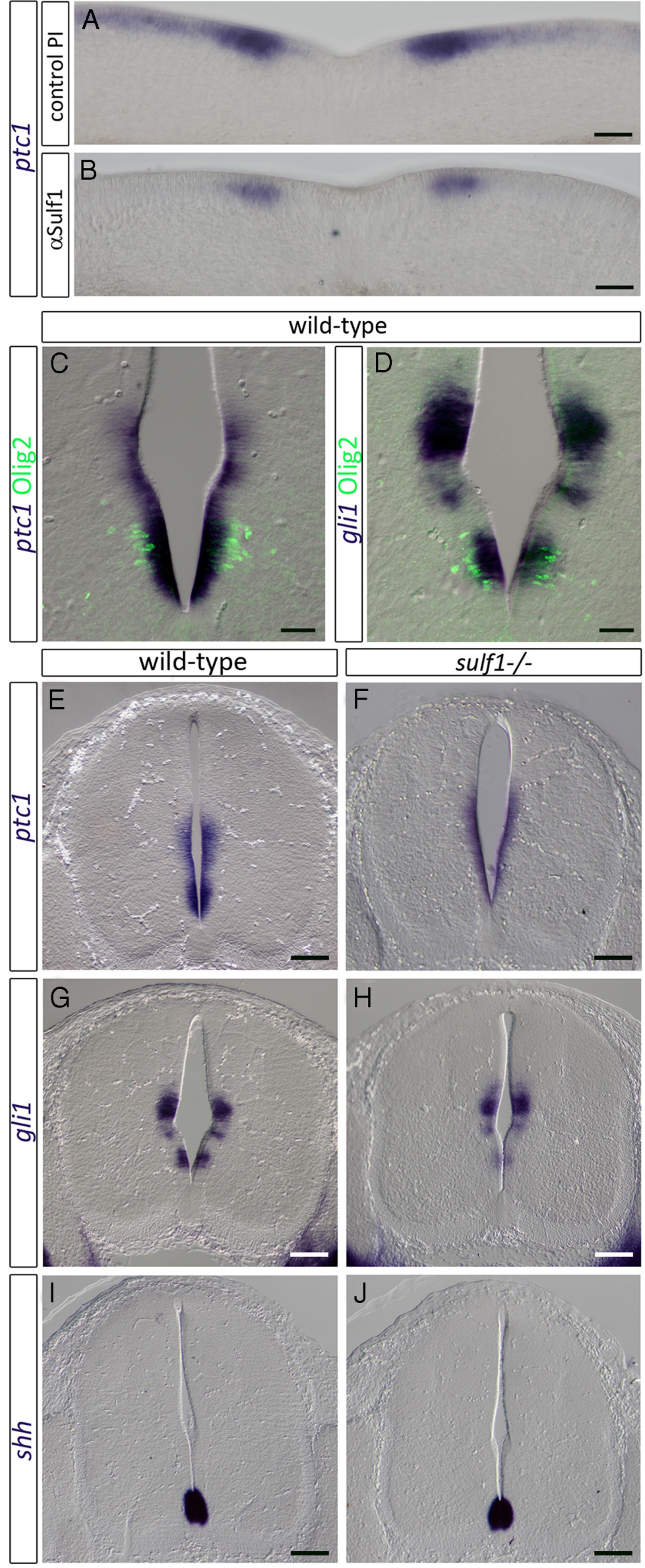

Sulf1 contributes to $\mathrm{Nkx} 2.2$ upregulation in Olig2 progenitors as they switch to OPC fate in mouse In chicken, a temporal change in dorsoventral patterning of the spinal cord has been reported to occur just before the MN-to-OPC fate switch. From E5 onward, the Nkx2.2 progenitor domain extends dorsally, within the pMN domain, resulting in formation of the $\mathrm{p}^{*}$ domain characterized by the coexpression of Olig2 and Nkx2.2 (Zhou et al., 2001; Fu et al., 2002; Agius et al., 2004). We reported previously that this upregulation of $\mathrm{Nkx} 2.2$ in Olig2 progenitors depends on Shh (Agius et al., 2004). Our present results showing impairment of Nkx2.2 domain extension after inactivation of Sulf1 in chicken spinal cord explants (Fig. $6 A^{\prime}, B^{\prime}$ ) bring additional support to a role for Sulf1 in activating Shh signaling at the time of the MN-to-OPC fate switch. In mouse embryos, coexpression of Olig2 and Nkx2.2 in ventral neural progenitors at the stage of OPC specification has been reported previously (Sun et al., 2001), and OPCs are also well known to upregulate $\mathrm{Nkx} 2.2$ expression while they migrate in the mantle zone (Qi et al., 2001; Fu et al., 2002). We performed double immunodetection experiments at various stages of development and observed that, in wild-type mouse embryos, at least a subpopulation of Olig2 progenitors in the pMN domain gained Nkx2.2 expression between E10.5 and E12.5 (Fig. 9A,B). However, the Nkx2.2 signal intensity in Olig2 progenitors was quite weak, reflecting a low level of expression. At E12.5, we found that $55 \%$ of Olig2 progenitors coexpressed $\mathrm{Nkx} 2.2(23.95 \pm 1.36, n=4)$. In sulf1 ${ }^{-/-}$ embryos, the number of Olig2/Nkx2.2coexpressing cells in the progenitor

$\leftarrow$

Figure 7. Sulf1 positively regulates expression of Shh target genes in the ventral embryonic spinal cord at the onset of OPC generation. $\boldsymbol{A}, \boldsymbol{B}$, Transverse sections of chicken spinal cord explants isolated at E4.5, maintained in culture for $2 \mathrm{~d}$ in the presence of preimmune serum (control $\mathrm{Pl}, \boldsymbol{A}$ ) or Sulf1 blocking antibody ( $\alpha$ Sulf1, $\boldsymbol{B})$, and processed for detection of ptc1 mRNA. Note decreased expression of ptc1 during treatment with $\alpha$ Sulf1 $(\boldsymbol{B})$ compared with control PI $(\boldsymbol{A})$. $(-\boldsymbol{J}$, Transverse spinal cord sections of E12.5 mouse embryos. $C, D$, ISH performed on wild-type embryos using ptc $1(C)$ and gli (D) probes, followed by immunodetection of Olig2. Confocal images of Olig2 staining (green) were overlaid with the brightfield image of the same section to position the $\mathrm{pMN}$ domain relative to cells expressing $p t c 1$ and gli1. $E-J$, Detection of $p t c 1$ $(\boldsymbol{E}, \boldsymbol{F})$, gli $(\boldsymbol{G}, \boldsymbol{H})$ and $\operatorname{shh}(\boldsymbol{I}, \boldsymbol{J}) \mathrm{mRNAs}$ on wild-type $(\boldsymbol{E}, \boldsymbol{G}, \boldsymbol{I})$ and sulf1 mutant $(\boldsymbol{F}, \boldsymbol{H}, \boldsymbol{J})$ embryos. Note decreased ptc1 and gli1 expressions in the ventral progenitor zone of sulf1 mutant embryos $(\boldsymbol{F}, \boldsymbol{H})$ compared with wild-type embryos $(\boldsymbol{E}, \boldsymbol{G})$. Scale bars: $A-D, 50 \mu \mathrm{m} ; \boldsymbol{E}-J, 100 \mu \mathrm{m}$. 


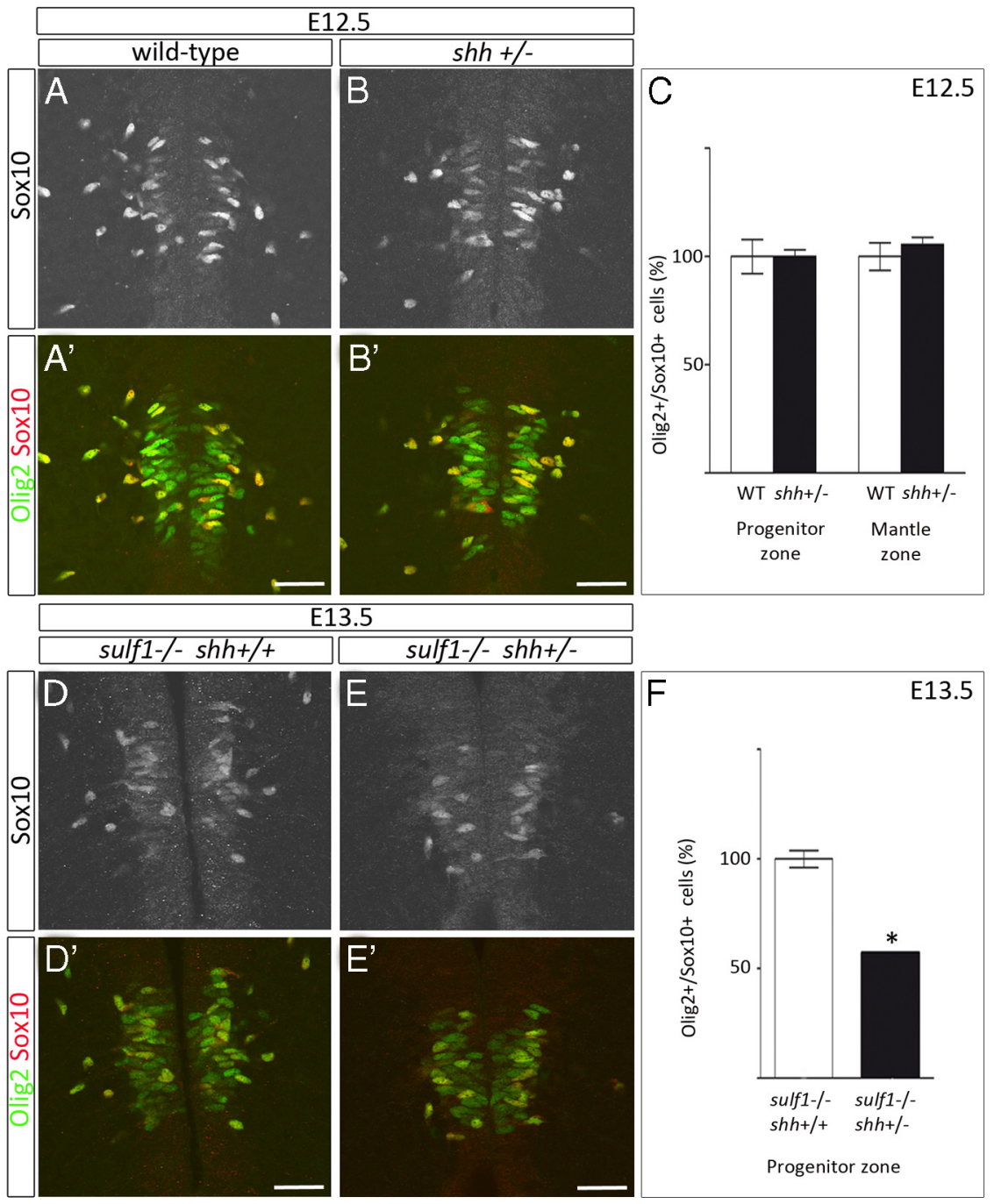

Figure 8. sulf1; shh compound mutants display severely reduced OPC specification. $A, B$, Double detections of Olig2 ( $g$ reen in $\boldsymbol{A}^{\prime}$, $\boldsymbol{B}^{\prime}$ ) and Sox10 (red in $\boldsymbol{A}^{\prime}, \boldsymbol{B}^{\prime}$ ) in the progenitor zone of E12.5 wild-type $\left(\boldsymbol{A}, \boldsymbol{A}^{\prime}\right)$ and $\mathrm{shh}^{+/-}\left(\boldsymbol{B}, \boldsymbol{B}^{\prime}\right)$ embryos. C, Quantification of Olig2/Sox10-coexpressing cells in wild-type and shh ${ }^{+/-}$embryos, in both the progenitor zone and the mantle zone. $\boldsymbol{D}, \boldsymbol{E}$, Double detections of Olig2 (green in $\boldsymbol{D}^{\prime}, \boldsymbol{E}^{\prime}$ ) and Sox10 (red in $\boldsymbol{D}^{\prime}, \boldsymbol{E}^{\prime}$ ) in the progenitor zone of E13.5 sulf1 ${ }^{-/-}$; shh ${ }^{+/+}\left(\boldsymbol{D}_{,} \boldsymbol{D}^{\prime}\right)$ and sulf $^{-/-}$; shh ${ }^{+/-}\left(\boldsymbol{E}, \boldsymbol{E}^{\prime}\right)$ littermate embryos. $\boldsymbol{F}$, Quantification of 0lig2/Sox10-coexpressing cells in the progenitor zone in the different genetic contexts indicated under bars. Cell numbers obtained for wild-type $(\boldsymbol{C})$ and sulf1 $1^{-/-} ;$shh $^{+/+}(\boldsymbol{F})$ embryos were arbitrarily set to $100 \%$. All other values were expressed relative to wild-type $(\boldsymbol{C})$ or sulf1 $1^{-/-} ; \mathrm{Shh}^{+/+}(\boldsymbol{F})$ levels and are presented as mean \pm SEM ( $\left.{ }^{*} p \leq 0.02\right)$. WT, Wild type. Scale bars, $50 \mu \mathrm{m}$.

zone was reduced with only $32 \%$ of Olig2 progenitors ( $14 \pm$ $1.22, n=4, p=0.02$ ) having upregulated $\mathrm{Nkx} 2.2$ at this stage (Fig. 9C).

Together, these results indicate that sulf1 impairment caused a $40 \%$ reduction in the number of Olig $2 / \mathrm{Nkx} 2.2$-coexpressing cells. Therefore, as observed in chicken, dorsal extension of Nkx2.2 expression in mouse embryos also depends on Sulf1 activity. Moreover, because Nkx2.2 is recognized as a direct target of Shh (Lei et al., 2006; Vokes et al., 2007; Lek et al., 2010), these results bring additional support to Sulf1 acting by positively regulating Shh signaling activity.

Sulf1 is not expressed in Olig2 progenitors and acts non-cell autonomously to positively regulate $\mathrm{Shh}$ responsive gene expression

To get additional insight on Sulf1 function in the ventral spinal cord, it was important to precisely position neural progenitors expressing Sulf1 relative to Olig2 progenitors. For this, we performed double detection of Sulf1 and Olig2 at E12.5 in mouse and E6 in chicken. Our results showed that, in both species, Sulf1expressing cells were located in the ventralmost region of the progenitor zone but were excluded from the Olig2-expressing domain (Fig. 10A,B). Therefore, Olig2 progenitors do not express Sulf1, opening the possibility that the enzyme induces their switch to the OPC fate by non-cell autonomously enhancing Shh activity. To investigate this possibility, we first examined expression of Shh-responsive genes relative to sulf1 domain of expression by double labeling for sulf1 and ptc1 or gli1 in E6 chicken spinal cord. Our results showed that the highest levels of $p t c 1$ and glil expression were detected in progenitors located dorsally to sulf1-expressing cells (Fig. 10C,D), in agreement with the possibility that Sulf1 would stimulate the response to Shh in dorsally adjacent cells. We next performed Sulf1 overexpression experiments using electroporation of a Sulf1-expressing vector in E4.5 chicken spinal cord. Misexpression of Sulf1 induced upregulation of $p t c 1$ after $2 \mathrm{~d}$ in culture, whereas electroporation of an empty vector did not modify its expression (Fig. $10 E, F)$. Importantly, cells displaying high levels of $p t c 1$ expression were located dorsally to and excluded from the ventralmost domain containing a high density of cells electroporated with the sulf1expressing vector (Fig. 10E). To determine whether ventrally localized Sulf1 overexpression may be sufficient to enhance OPC generation, we analyzed Olig2 expression after electroporation of the sulf1-expressing vector. The number of OPCs migrating in the marginal zone was markedly elevated in the electroporated side compared with the contralateral side $(n=5)$ or with control explants electroporated with an empty vector $(n=3$; Fig. $10 G, H)$. These results indicate that neural progenitors overexpressing Sulf1 gain the ability to elevate Shh activity in dorsally located cells and stimulate OPC generation from Olig2 progenitors.

Together, these data suggest a role for Sulf1 as an enhancer of Shh activity in immediately neighboring cells.

\section{Discussion}

Olig2 progenitors of the embryonic spinal cord change their fate during a short developmental window from the production of MNs to that of OPCs. Here we report a novel function for Sulf1 as an enzyme involved in the control of this neuroglial switch in both mouse and chicken.

We show that lack of Sulf1 activity leads to defective OPC generation. This does not result from an initial depletion in the Olig2 progenitor pool, which is not affected in sulf1 mutant em- 


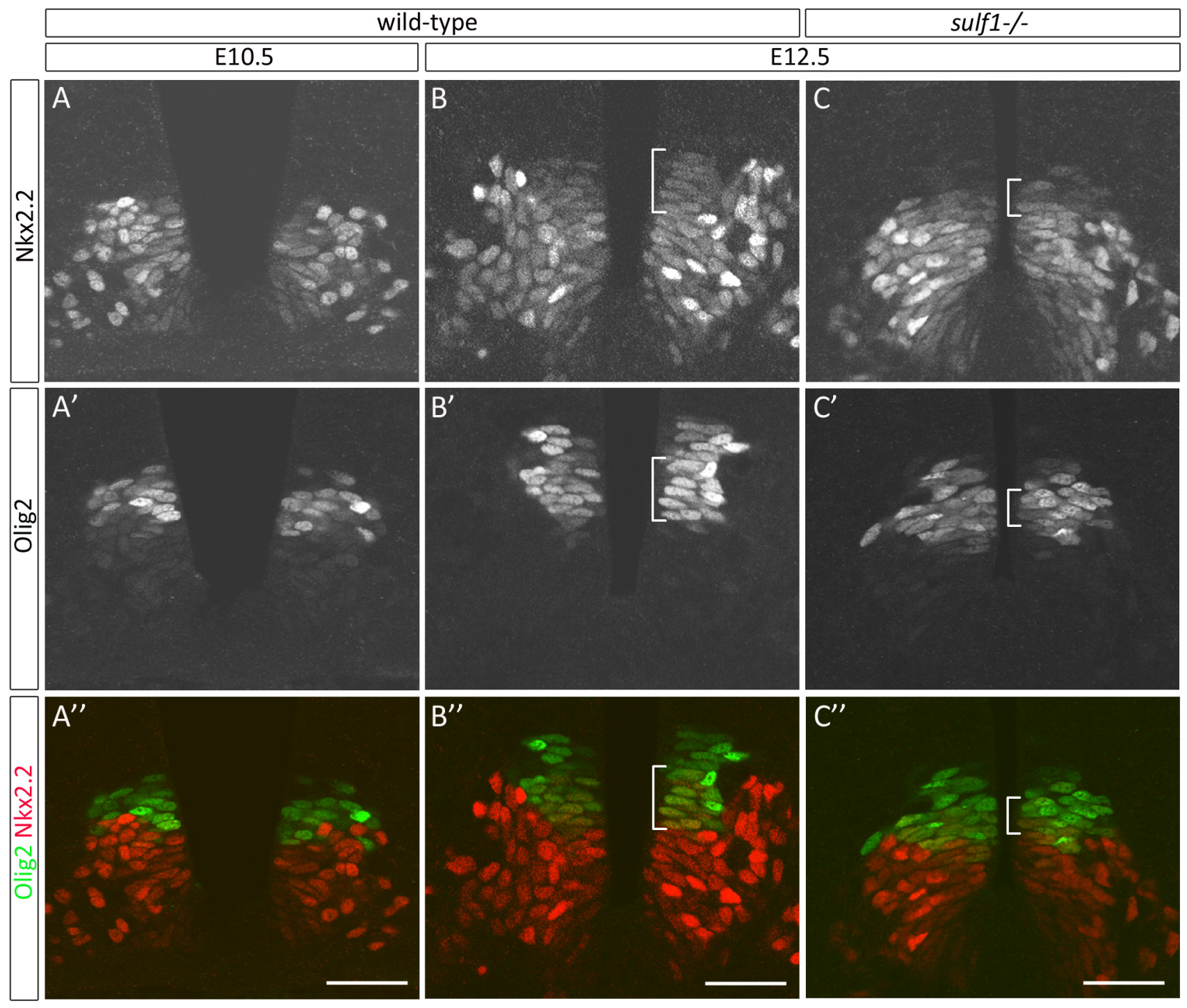

Figure 9. Nkx2.2 upregulation in Olig2 progenitors occurs at the stage of MN-to-OPC fate switch in mouse embryos and depends on Sulf1 function. $A-C$, Double detection of Nkx2.2 (A-C, red in $\left.\boldsymbol{A}^{\prime \prime}-\boldsymbol{C}^{\prime \prime}\right)$ and Olig2 $\left(\boldsymbol{A}^{\prime}-\boldsymbol{C}^{\prime}\right.$, green in $\left.\boldsymbol{A}^{\prime \prime}-\boldsymbol{C}^{\prime \prime}\right)$ on transverse sections of E10.5 $(\boldsymbol{A})$ and E12.5 $(\boldsymbol{B})$ wild-type and of E12.5 sulf1 mutant $(\boldsymbol{C})$ embryos. Note dorsal extension of the Nkx2.2-expressing domain between E10.5 (A) and E12.5 $(\boldsymbol{B})$ in wild-type embryos, which is reduced in sulf1 mutant embryos (compare $\boldsymbol{B}$ with $\boldsymbol{C}$ ). Although only rare cells coexpress 0 lig2 and Nkx2.2 at E10.5 ( $\left.\boldsymbol{A}^{\prime \prime}\right)$, a broad overlapping between these two transcription factors was visualized in E12.5 wild-type embryos (bracket in $\boldsymbol{B}^{\prime \prime}$ ). In E12.5 sulf1 mutant spinal cords, only few cells coexpress 0 lig2 and Nkx2.2 (bracket in $\boldsymbol{C}^{\prime \prime}$ ) compared with wild-type siblings (compare $\boldsymbol{C}^{\prime \prime}$ with $\boldsymbol{B}^{\prime \prime}$ ). Scale bars, $50 \mu \mathrm{m}$.

bryonic spinal cord at the onset of OPC production. Instead, this defect relies on the reduction in the number of Olig2 progenitors that should have turned off the MN program to switch to the OPC fate. As a consequence, a remarkable phenotype in sulf1deficient spinal cords is the concomitant generation of MNs and OPCs from Olig2 progenitors, a situation never encountered in normal conditions, in which MN and OPC productions are timely separated events in both mouse and chicken (Kessaris et al., 2001; Soula et al., 2001; our present results). Therefore, Sulf1 activity appears to be required for both cessation of $\mathrm{MN}$ production and optimal recruitment of Olig2 progenitors to generate OPCs at the right time.

Experiments performed in chicken show that impairment of Sulf1 activity at the stage of the MN-to-OPC fate switch is sufficient to reproduce the phenotype observed in sulf1 mutant mouse embryos, supporting the view that Sulf1 activity is required precisely when Olig2 progenitors change their fate. In support of this, knockdown of sulf1 in floor plate cells has no effect on OPC generation, pointing to the major contribution of sulf1 upregulated in Nkx2.2-expressing cells of the p3 domain just before the onset of OPC generation (Braquart-Varnier et al., 2004). We previously reported that, in chicken, OPC specification depends on a rise in Shh activity occurring precisely at this stage (Danesin et al., 2006). Our present results showing upregulation of Nkx2.2 in Olig2 progenitors at the stage of the MN-toOPC fate switch in the mouse strongly argue in favor of a timely regulated elevation of Shh activity also conserved in mice. Indeed, Nkx2.2 expression depends on a high level of Shh activity, and this transcription factor has also been reported to intrinsically strengthen Shh response in neural progenitors (Novitch et al., 2001; Lei et al., 2006; Dessaud et al., 2007; Lek et al., 2010). Our data showing genetic interaction between sulf1 and shh in the mouse, as well as downregulation of Shh-responsive genes in Olig2 progenitors after inactivation of Sulf1, establish a critical role for the enzyme in controlling Shh activity in the developing ventral spinal cord. Both upregulation and maintenance of olig2 

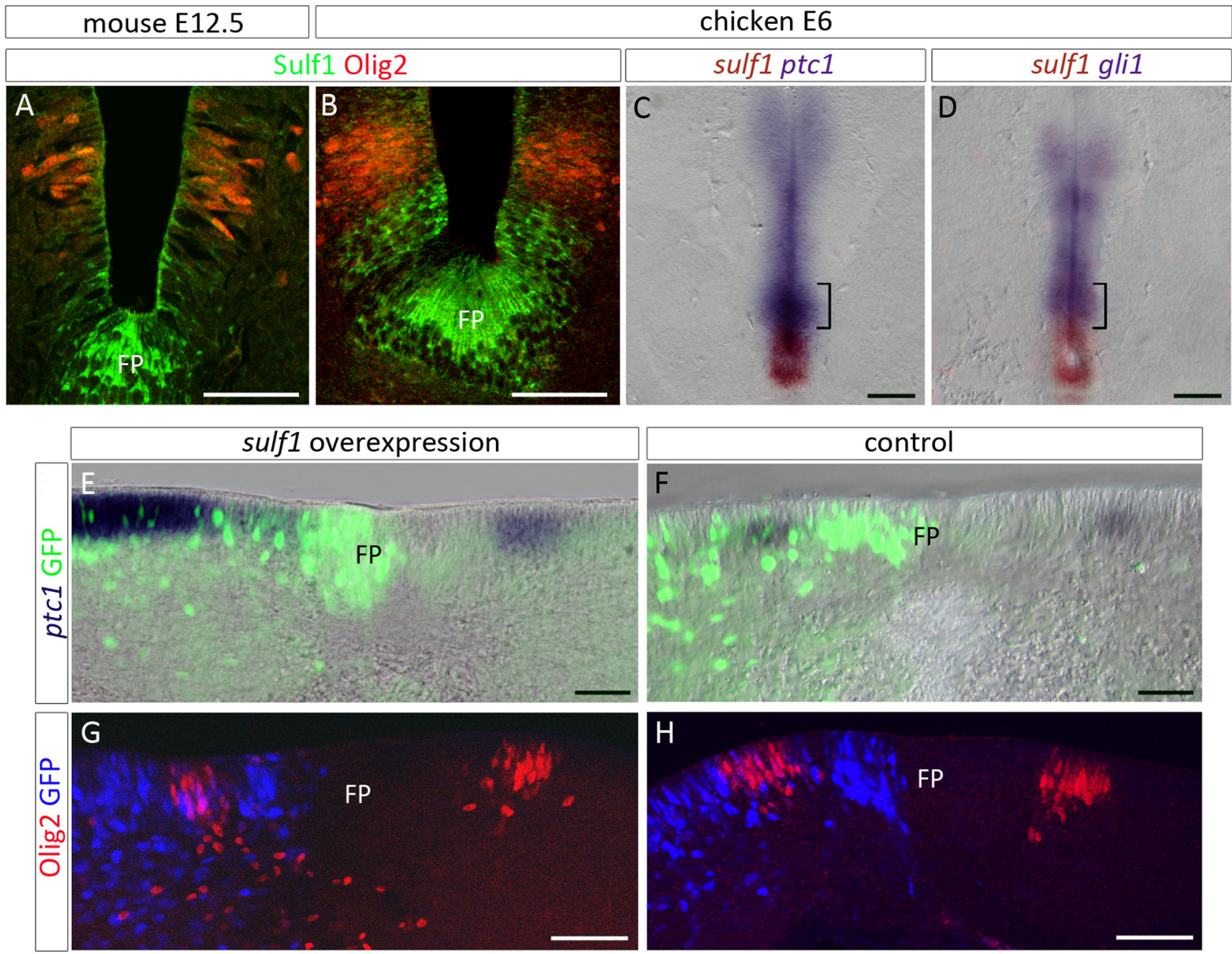

Figure 10. Sulf1 is not expressed in Olig2 progenitors and acts non-cell autonomously to positively activate Shh signaling activity. $\boldsymbol{A}, \boldsymbol{B}$, Transverse sections of E12.5 mouse $(\boldsymbol{A})$ and $\mathrm{E} 6$ chicken $(\boldsymbol{B})$ embryonic spinal cords, double immunolabeled for 0lig2 (red) and Sulf1 (green). Sulf1 is detectable in floor plate (FP) cells as well as in the ventralmost neural progenitors of the $\mathrm{p} 3$ domain but not in dorsally located Olig2-expressing cells. C, D, Double detections of sulf1 (red) and ptc1 (purple in $\boldsymbol{C}$ ) or glit (purple in D) mRNAs showing high level of expression for both Shh responsive genes in neural progenitors (brackets) located dorsally to sulf1-expressing cells. $\boldsymbol{E}-\boldsymbol{H}$, Transverse sections of chicken spinal cord explants isolated at E4.5 and maintained in culture for $2 \mathrm{~d}$. $\boldsymbol{E}, \boldsymbol{F}$, Detection of ptc1 mRNA (purple) after electroporation of sulf1-expressing vector (green, $\boldsymbol{E}$ ) or control empty vector (green, $\boldsymbol{F}$ ). Note upregulation of ptc1 in neural progenitors located dorsally relatively to the domain containing high density of sulf1-overexpressing cells $(\boldsymbol{E})$. $\boldsymbol{G}, \boldsymbol{H}$, Immunodetection of Olig2 (red) after electroporation with the sulf1-expressing vector (blue, $\boldsymbol{G}$ ) or control empty vector (blue, $\boldsymbol{H})$ showing a marked increase in the population of Olig2-positive cells migrating in the mantle zone of explants electroporated with the sulf1-expressing vector $(\boldsymbol{G})$ compared with the contralateral side of explants or with explants electroporated with the control vector $(\boldsymbol{H})$. Scale bars: $\boldsymbol{A}, \boldsymbol{B}, \boldsymbol{E}-\boldsymbol{H}, 50 \mu \mathrm{m} ; \boldsymbol{C}, \boldsymbol{D}, 100 \mu \mathrm{m}$.

expression in the ventral neural tube is well known to depend on Shh (Lu et al., 2000; Zhou et al., 2000; Agius et al., 2004). Because the pool of Olig2 progenitors is not affected in E12.5 sulf1 mutant embryos, the enzyme appears to act as a positive modulator but not as an obligatory component of the Shh signaling pathway. Therefore, Sulf1 should be viewed as a temporal regulator of Shh signaling in the developing spinal cord involved in elevating Shh activity to trigger Olig2 progenitor cell fate change.

One attractive hypothesis, supported by the lowered intensity of the Olig2 signal observed in the progenitor zone of sulf1 mutant mouse embryos, is that Sulf1-dependent elevation of Shh might contribute to upregulate Olig2 expression in at least subsets of $\mathrm{pMN}$ progenitors. Indeed, variations of Olig2 expression levels in pMN cells have been reported previously to regulate $\mathrm{MN}$ or OPC generation: downregulation of Olig2 is required to release the repressive block of this factor on neurogenesis, whereas high Olig2 expression triggers progenitors to follow an OPC fate (Novitch et al., 2001; Qi et al., 2003; Liu et al., 2007). Another possible level of regulation might be linked to the control of Olig2 phosphorylation status reported recently to guide its activity in promoting the MN or OPC fate choice (Li et al., 2011). Our data also open the possibility that $\mathrm{Nkx} 2.2$ might be part of the regulatory machinery that triggers the OPC fate choice in mouse, as reported in chicken (Zhou et al., 2001). Finally, the phenotype of sulf1 mutant embryos is very reminiscent of that observed after ablation of Sox9 in neural progenitors of aged-matched embryos (Stolt et al., 2003). Sox9 upregulates expression of the gliogenic factor NFIA (nuclear factor 1A), which further acts in coordination with Olig2 to favor the OPC fate choice of Olig2 progenitors (Deneen et al., 2006; Hochstim et al., 2008; Kang et al., 2012). Because sox 9 expression in ventral neural progenitors is also regulated by Shh (Scott et al., 2010), this transcription factor represents another possible target of Sulf1-dependent timely regulated fate of Olig2 progenitors.

Our data raise the question of the molecular mechanisms underlying the Sulf1-dependent temporal regulation of Shh activity. We know from our previous work that Sulf1 is involved in shaping the Shh/Hh gradient at the apical surface of chicken neural 
progenitors and Drosophila wing disc cells (Danesin et al., 2006; Wojcinski et al., 2011). Sulf1 is well known to remove 6O-sulfate groups on HS chains of HSPGs, the only known sulfate moiety post-synthetically edited (Lamanna et al., 2007). Accordingly, loss of Sulf1 in mice selectively increases the abundance of trisulfated disaccharides and proportionately decreases disulfated ones (Ai et al., 2006; Lamanna et al., 2006; Nagamine et al., 2012). HSPGs are currently viewed as major regulators for morphogen gradient formation during development (Bishop et al., 2007), and Shh is well known to interact with HS chains, mainly by its Cardin-Weintraub motif (Carrasco et al., 2005; Zhang et al., 2007; Chang et al., 2011; Farshi et al., 2011). Importantly, Shh is known to preferentially bind to HS chains having a high level of sulfation (Carrasco et al., 2005; Zhang et al., 2007; Dierker et al., 2009). Therefore, as reported for other signaling molecules (Ai et al., 2003; Viviano et al., 2004; Freeman et al., 2008), Sulf1 activity is likely to lower Shh/HSPGs interaction. Because Sulf1 is not expressed in Olig2 progenitors themselves when these cells respond to high Shh activity, i.e., E12.5 in mouse and E6 in chicken, it is unlikely that Sulf1 acts locally. However, keeping in mind that the enzyme is secreted, the possibility that Sulf1 reaches the surface of Olig2 progenitors cannot be totally excluded. A more convincing explanation that fits well with our results is that Sulf1, by eliminating 6O-sulfate groups on HS chains, locally lowers Shh/HSPG interaction and thereby promotes Shh release from the surface of $\mathrm{p} 3$ progenitors. Subsequently, because of higher availability of the diffusible form of Shh free to travel dorsally, higher doses of the morphogen are provided to neighboring Olig2 progenitors. Accordingly, in chicken spinal cord explants, ventral cells overexpressing Sulf1 induce ectopic $p t c 1$ upregulation in neural progenitors located dorsally but not in Sulf1overexpressing cells themselves. Moreover, ptc1 and gli1 mRNAs are undetectable in the ventralmost neural progenitors of E6 chicken spinal cord, indicating low or no Shh activity in Sulf1expressing cell themselves, again in agreement with Sulf1 acting by favoring Shh release from these cells. The fact that $\mathrm{p} 3$ progenitors maintain Nkx2.2 as they gain Sulf1 expression (our present results; Braquart-varnier et al., 2004) does not disagree with this proposal because Shh, known to be required for switching on $n k x 2.2$ in ventral neural progenitors, is dispensable for its maintenance later on (Agius et al., 2004; Allen et al., 2011).

Our present work, by characterizing Sulf1 as a positive regulator of the Shh-dependent Olig2 progenitor cell fate change, highlights a role for HSPGs in the temporal control of the MNto-OPC fate switch. These components of the extracellular matrix have been reported previously to control the proliferative activity of Shh in the mouse developing cerebellum (Rubin et al., 2002; Chan et al., 2009). However, Shh/HSPG interactions have been found dispensable for achieving Shh-dependent patterning of the ventral neural tube (Chan et al., 2009). In agreement with the aforementioned conclusion, our data indicate that Sulf1 is also dispensable for formation of the ventral progenitor domains that express Nkx2.2 and Olig2, indicating that at least the modulation of 6O-sulfation on HSPGs is not critically required for Shh patterning activity in the ventral neural tube. However, the involvement of Sulf1 in controlling Shh-dependent cell fate change, long after establishment of the ventral neural tube patterning, indicates that Shh signaling becomes dependent on HSPG regulation as development proceeds. Because expression of HSPGs is tightly controlled during development (Yan and Lin, 2009), it is tempting to speculate that changes in components of the extracellular matrix might represent an important level of regulation of Shh activity. In support of this, the HSPG biosynthetic enzyme
Ext1 is upregulated in the ventral developing spinal cord precisely at the stage of the MN-to-OPC fate switch in chicken (Danesin et al., 2006).

Overall, our work, by characterizing Sulf1 as a positive regulator of the MN-to-OPC fate switch, sheds new light on the mechanisms underlying the timely regulated activation of Shh signaling responsible for $\mathrm{OPC}$ specification at the expense of $\mathrm{MN}$ production in the embryonic ventral spinal cord.

\section{References}

Agius E, Soukkarieh C, Danesin C, Kan P, Takebayashi H, Soula C, Cochard P (2004) Converse control of oligodendrocyte and astrocyte lineage development by Sonic hedgehog in the chick spinal cord. Dev Biol 270:308321. CrossRef Medline

Agius E, Decker Y, Soukkarieh C, Soula C, Cochard P (2010) Role of BMPs in controlling the spatial and temporal origin of GFAP astrocytes in the embryonic spinal cord. Dev Biol 344:611-620. CrossRef Medline

Ai X, Do AT, Lozynska O, Kusche-Gullberg M, Lindahl U, Emerson CP Jr (2003) QSulf1 remodels the 6-O sulfation states of cell surface heparan sulfate proteoglycans to promote Wnt signaling. J Cell Biol 162:341-351. CrossRef Medline

Ai X, Do AT, Kusche-Gullberg M, Lindahl U, Lu K, Emerson CP Jr (2006) Substrate specificity and domain functions of extracellular heparan sulfate 6-O-endosulfatases, QSulf1 and QSulf2. J Biol Chem 281:4969-4976. CrossRef Medline

Ai X, Kitazawa T, Do AT, Kusche-Gullberg M, Labosky PA, Emerson CP Jr (2007) SULF1 and SULF2 regulate heparan sulfate-mediated GDNF signaling for esophageal innervation. Development 134:3327-3338. CrossRef Medline

Allen BL, Song JY, Izzi L, Althaus IW, Kang JS, Charron F, Krauss RS, McMahon AP (2011) Overlapping roles and collective requirement for the coreceptors GAS1, CDO, and BOC in SHH pathway function. Dev Cell 20:775-787. CrossRef Medline

Bai CB, Auerbach W, Lee JS, Stephen D, Joyner AL (2002) Gli2, but not Gli1, is required for initial Shh signaling and ectopic activation of the Shh pathway. Development 129:4753-4761. Medline

Bai CB, Stephen D, Joyner AL (2004) All mouse ventral spinal cord patterning by hedgehog is Gli dependent and involves an activator function of Gli3. Dev Cell 6:103-115. CrossRef Medline

Bilican B, Fiore-Heriche C, Compston A, Allen ND, Chandran S (2008) Induction of Olig2 precursors by FGF involves BMP signalling blockade at the Smad level. PLoS One 3:e2863. CrossRef Medline

Bishop JR, Schuksz M, Esko JD (2007) Heparan sulphate proteoglycans fine-tune mammalian physiology. Nature 446:1030-1037. CrossRef Medline

Braquart-Varnier C, Danesin C, Clouscard-Martinato C, Agius E, Escalas N, Benazeraf B, Ai X, Emerson C, Cochard P, Soula C (2004) A subtractive approach to characterize genes with regionalized expression in the gliogenic ventral neuroepithelium: identification of chick sulfatase 1 as a new oligodendrocyte lineage gene. Mol Cell Neurosci 25:612-628. CrossRef Medline

Briscoe J, Novitch BG (2008) Regulatory pathways linking progenitor patterning, cell fates and neurogenesis in the ventral neural tube. Philos Trans R Soc Lond B Biol Sci 363:57-70. CrossRef Medline

Cai J, Qi Y, Hu X, Tan M, Liu Z, Zhang J, Li Q, Sander M, Qiu M (2005) Generation of oligodendrocyte precursor cells from mouse dorsal spinal cord independent of Nkx6 regulation and Shh signaling. Neuron 45:41-53. CrossRef Medline

Carrasco H, Olivares GH, Faunes F, Oliva C, Larraín J (2005) Heparan sulfate proteoglycans exert positive and negative effects in Shh activity. J Cell Biochem 96:831-838. CrossRef Medline

Chan JA, Balasubramanian S, Witt RM, Nazemi KJ, Choi Y, Pazyra-Murphy MF, Walsh CO, Thompson M, Segal RA (2009) Proteoglycan interactions with Sonic Hedgehog specify mitogenic responses. Nat Neurosci 12:409-417. CrossRef Medline

Chandran S, Kato H, Gerreli D, Compston A, Svendsen CN, Allen ND (2003) FGF-dependent generation of oligodendrocytes by a hedgehogindependent pathway. Development 130:6599-6609. CrossRef Medline

Chang SC, Mulloy B, Magee AI, Couchman JR (2011) Two distinct sites in sonic Hedgehog combine for heparan sulfate interactions and cell signaling functions. J Biol Chem 286:44391-44402. CrossRef Medline 
Danesin C, Agius E, Escalas N, Ai X, Emerson C, Cochard P, Soula C (2006) Ventral neural progenitors switch toward an oligodendroglial fate in response to increased Sonic hedgehog (Shh) activity: involvement of Sulfatase 1 in modulating Shh signaling in the ventral spinal cord. J Neurosci 26:5037-5048. CrossRef Medline

Das RM, Van Hateren NJ, Howell GR, Farrell ER, Bangs FK, Porteous VC, Manning EM, McGrew MJ, Ohyama K, Sacco MA, Halley PA, Sang HM, Storey KG, Placzek M, Tickle C, Nair VK, Wilson SA (2006) A robust system for RNA interference in the chicken using a modified microRNA operon. Dev Biol 294:554-563. CrossRef Medline

Deneen B, Ho R, Lukaszewicz A, Hochstim CJ, Gronostajski RM, Anderson DJ (2006) The transcription factor NFIA controls the onset of gliogenesis in the developing spinal cord. Neuron 52:953-968. CrossRef Medline

Dessaud E, Yang LL, Hill K, Cox B, Ulloa F, Ribeiro A, Mynett A, Novitch BG, Briscoe J (2007) Interpretation of the sonic hedgehog morphogen gradient by a temporal adaptation mechanism. Nature 450:717-720. CrossRef Medline

Dhoot GK, Gustafsson MK, Ai X, Sun W, Standiford DM, Emerson CP Jr (2001) Regulation of Wnt signaling and embryo patterning by an extracellular sulfatase. Science 293:1663-1666. CrossRef Medline

Dierker T, Dreier R, Migone M, Hamer S, Grobe K (2009) Heparan sulfate and transglutaminase activity are required for the formation of covalently cross-linked hedgehog oligomers. J Biol Chem 284:32562-32571. CrossRef Medline

Dubois L, Bally-Cuif L, Crozatier M, Moreau J, Paquereau L, Vincent A (1998) XCoe2, a transcription factor of the Col/Olf-1/EBF family involved in the specification of primary neurons in Xenopus. Curr Biol 8:199-209. CrossRef Medline

Ericson J, Thor S, Edlund T, Jessell TM, Yamada T (1992) Early stages of motor neuron differentiation revealed by expression of homeobox gene Islet-1. Science 256:1555-1560. CrossRef Medline

Ericson J, Morton S, Kawakami A, Roelink H, Jessell TM (1996) Two critical periods of Sonic Hedgehog signaling required for the specification of motor neuron identity. Cell 87:661-673. CrossRef Medline

Farshi P, Ohlig S, Pickhinke U, Höing S, Jochmann K, Lawrence R, Dreier R, Dierker T, Grobe K (2011) Dual roles of the Cardin-Weintraub motif in multimeric Sonic hedgehog. J Biol Chem 286:23608-23619. CrossRef Medline

Freeman SD, Moore WM, Guiral EC, Holme AD, Turnbull JE, Pownall ME (2008) Extracellular regulation of developmental cell signaling by XtSulf1. Dev Biol 320:436-445. CrossRef Medline

Fu H, Qi Y, Tan M, Cai J, Takebayashi H, Nakafuku M, Richardson W, Qiu M (2002) Dual origin of spinal oligodendrocyte progenitors and evidence for the cooperative role of Olig2 and Nkx2.2 in the control of oligodendrocyte differentiation. Development 129:681-693. Medline

Garel S, Marín F, Mattéi MG, Vesque C, Vincent A, Charnay P (1997) Family of Ebf/Olf-1-related genes potentially involved in neuronal differentiation and regional specification in the central nervous system. Dev Dyn 210:191-205. CrossRef Medline

Gill R, Hitchins L, Fletcher F, Dhoot GK (2010) Sulf1A and HGF regulate satellite-cell growth. J Cell Sci 123:1873-1883. CrossRef Medline

Goodrich LV, Johnson RL, Milenkovic L, McMahon JA, Scott MP (1996) Conservation of the hedgehog/patched signaling pathway from flies to mice: induction of a mouse patched gene by Hedgehog. Genes Dev 10: 301-312. CrossRef Medline

Gritli-Linde A, Lewis P, McMahon AP, Linde A (2001) The whereabouts of a morphogen: direct evidence for short- and graded long-range activity of hedgehog signaling peptides. Dev Biol 236:364-386. CrossRef Medline

Hamburger V, Hamilton HL (1992) A series of normal stages in the development of the chick embryo. 1951. Dev Dyn 195:231-272. CrossRef Medline

Hochstim C, Deneen B, Lukaszewicz A, Zhou Q, Anderson DJ (2008) Identification of positionally distinct astrocyte subtypes whose identities are specified by a homeodomain code. Cell 133:510-522. CrossRef Medline

Kalus I, Salmen B, Viebahn C, von Figura K, Schmitz D, D'Hooge R, Dierks T (2009) Differential involvement of the extracellular 6-O-endosulfatases Sulf1 and Sulf2 in brain development and neuronal and behavioural plasticity. J Cell Mol Med 13:4505-4521. CrossRef Medline

Kang P, Lee HK, Glasgow SM, Finley M, Donti T, Gaber ZB, Graham BH, Foster AE, Novitch BG, Gronostajski RM, Deneen B (2012) Sox9 and NFIA coordinate a transcriptional regulatory cascade during the initiation of gliogenesis. Neuron 74:79-94. CrossRef Medline
Kessaris N, Pringle N, Richardson WD (2001) Ventral neurogenesis and the neuron-glial switch. Neuron 31:677-680. CrossRef Medline

Kessaris N, Jamen F, Rubin LL, Richardson WD (2004) Cooperation between sonic hedgehog and fibroblast growth factor/MAPK signalling pathways in neocortical precursors. Development 131:1289-1298. CrossRef Medline

Kessaris N, Fogarty M, Iannarelli P, Grist M, Wegner M, Richardson WD (2006) Competing waves of oligodendrocytes in the forebrain and postnatal elimination of an embryonic lineage. Nat Neurosci 9:173-179. CrossRef Medline

Kessaris N, Pringle N, Richardson WD (2008) Specification of CNS glia from neural stem cells in the embryonic neuroepithelium. Philos Trans R Soc Lond B Biol Sci 363:71-85. CrossRef Medline

Kuhlbrodt K, Herbarth B, Sock E, Hermans-Borgmeyer I, Wegner M (1998) Sox10, a novel transcriptional modulator in glial cells. J Neurosci 18:237250. Medline

Lamanna WC, Baldwin RJ, Padva M, Kalus I, Ten Dam G, van Kuppevelt TH, Gallagher JT, von Figura K, Dierks T, Merry CL (2006) Heparan sulfate 6-O-endosulfatases: discrete in vivo activities and functional cooperativity. Biochem J 400:63-73. CrossRef Medline

Lamanna WC, Kalus I, Padva M, Baldwin RJ, Merry CL, Dierks T (2007) The heparanome- the enigma of encoding and decoding heparan sulfate sulfation. J Biotechnol 129:290-307. CrossRef Medline

Langseth AJ, Munji RN, Choe Y, Huynh T, Pozniak CD, Pleasure SJ (2010) Wnts influence the timing and efficiency of oligodendrocyte precursor cell generation in the telencephalon. J Neurosci 30:13367-13372. CrossRef Medline

Lei Q, Jeong Y, Misra K, Li S, Zelman AK, Epstein DJ, Matise MP (2006) Wnt signaling inhibitors regulate the transcriptional response to morphogenetic Shh-Gli signaling in the neural tube. Dev Cell 11:325-337. CrossRef Medline

Lek M, Dias JM, Marklund U, Uhde CW, Kurdija S, Lei Q, Sussel L, Rubenstein JL, Matise MP, Arnold HH, Jessell TM, Ericson J (2010) A homeodomain feedback circuit underlies step-function interpretation of a Shh morphogen gradient during ventral neural patterning. Development 137: 4051-4060. CrossRef Medline

Li H, de Faria JP, Andrew P, Nitarska J, Richardson WD (2011) Phosphorylation regulates OLIG2 cofactor choice and the motor neuronoligodendrocyte fate switch. Neuron 69:918-929. CrossRef Medline

Liu Z, Hu X, Cai J, Liu B, Peng X, Wegner M, Qiu M (2007) Induction of oligodendrocyte differentiation by Olig2 and Sox10: evidence for reciprocal interactions and dosage-dependent mechanisms. Dev Biol 302:683693. CrossRef Medline

Lu QR, Yuk D, Alberta JA, Zhu Z, Pawlitzky I, Chan J, McMahon AP, Stiles CD, Rowitch DH (2000) Sonic hedgehog-regulated oligodendrocyte lineage genes encoding bHLH proteins in the mammalian central nervous system. Neuron 25:317-329. CrossRef Medline

Mekki-Dauriac S, Agius E, Kan P, Cochard P (2002) Bone morphogenetic proteins negatively control oligodendrocyte precursor specification in the chick spinal cord. Development 129:5117-5130. Medline

Miller RH, Dinsio K, Wang R, Geertman R, Maier CE, Hall AK (2004) Patterning of spinal cord oligodendrocyte development by dorsally derived BMP4. J Neurosci Res 76:9-19. CrossRef Medline

Morimoto-Tomita M, Uchimura K, Werb Z, Hemmerich S, Rosen SD (2002) Cloning and characterization of two extracellular heparindegrading endosulfatases in mice and humans. J Biol Chem 277: 49175-49185. CrossRef Medline

Nagamine S, Tamba M, Ishimine H, Araki K, Shiomi K, Okada T, Ohto T, Kunita S, Takahashi S, Wismans RG, van Kuppevelt TH, Masu M, KeinoMasu K (2012) Organ-specific sulfation patterns of heparan sulfate generated by extracellular sulfatases Sulf1 and Sulf2 in mice. J Biol Chem 287:9579-9590. CrossRef Medline

Novitch BG, Chen AI, Jessell TM (2001) Coordinate regulation of motor neuron subtype identity and pan-neuronal properties by the bHLH repressor Olig2. Neuron 31:773-789. CrossRef Medline

Orentas DM, Hayes JE, Dyer KL, Miller RH (1999) Sonic hedgehog signaling is required during the appearance of spinal cord oligodendrocyte precursors. Development 126:2419-2429. Medline

Park HC, Shin J, Appel B (2004) Spatial and temporal regulation of ventral spinal cord precursor specification by Hedgehog signaling. Development 131:5959-5969. CrossRef Medline

Poncet C, Soula C, Trousse F, Kan P, Hirsinger E, Pourquié O, Duprat AM, 
Cochard P (1996) Induction of oligodendrocyte progenitors in the trunk neural tube by ventralizing signals: effects of notochord and floor plate grafts, and of sonic hedgehog. Mech Dev 60:13-32. CrossRef Medline

Pringle NP, Yu WP, Guthrie S, Roelink H, Lumsden A, Peterson AC, Richardson WD (1996) Determination of neuroepithelial cell fate: induction of the oligodendrocyte lineage by ventral midline cells and sonic hedgehog. Dev Biol 177:30-42. CrossRef Medline

Qi Y, Cai J, Wu Y, Wu R, Lee J, Fu H, Rao M, Sussel L, Rubenstein J, Qiu M (2001) Control of oligodendrocyte differentiation by the Nkx2.2 homeodomain transcription factor. Development 128:2723-2733. Medline

Qi Y, Tan M, Hui CC, Qiu M (2003) Gli2 is required for normal Shh signaling and oligodendrocyte development in the spinal cord. Mol Cell Neurosci 23:440-450. CrossRef Medline

Ratzka A, Kalus I, Moser M, Dierks T, Mundlos S, Vortkamp A (2008) Redundant function of the heparan sulfate 6-O-endosulfatases Sulf1 and Sulf2 during skeletal development. Dev Dyn 237:339-353. CrossRef Medline

Richardson WD, Smith HK, Sun T, Pringle NP, Hall A, Woodruff R (2000) Oligodendrocyte lineage and the motor neuron connection. Glia 29:136142. CrossRef Medline

Rowitch DH (2004) Glial specification in the vertebrate neural tube. Nat Rev Neurosci 5:409-419. CrossRef Medline

Rowitch DH, Kriegstein AR (2010) Developmental genetics of vertebrate glial-cell specification. Nature 468:214-222. CrossRef Medline

Rubin JB, Choi Y, Segal RA (2002) Cerebellar proteoglycans regulate sonic hedgehog responses during development. Development 129:2223-2232. Medline

Scardigli R, Schuurmans C, Gradwohl G, Guillemot F (2001) Crossregulation between Neurogenin 2 and pathways specifying neuronal identity in the spinal cord. Neuron 31:203-217. CrossRef Medline

Scott CE, Wynn SL, Sesay A, Cruz C, Cheung M, Gomez Gaviro MV, Booth S, Gao B, Cheah KS, Lovell-Badge R, Briscoe J (2010) SOX9 induces and maintains neural stem cells. Nat Neurosci 13:1181-1189. CrossRef Medline

Soula C, Danesin C, Kan P, Grob M, Poncet C, Cochard P (2001) Distinct sites of origin of oligodendrocytes and somatic motoneurons in the chick spinal cord: oligodendrocytes arise from $\mathrm{Nkx} 2.2$-expressing progenitors by a Shh-dependent mechanism. Development 128:1369-1379. Medline

St-Jacques B, Dassule HR, Karavanova I, Botchkarev VA, Li J, Danielian PS, McMahon JA, Lewis PM, Paus R, McMahon AP (1998) Sonic hedgehog signaling is essential for hair development. Curr Biol 8:1058-1068. CrossRef Medline

Stolt CC, Rehberg S, Ader M, Lommes P, Riethmacher D, Schachner M, Bartsch U, Wegner M (2002) Terminal differentiation of myelinforming oligodendrocytes depends on the transcription factor Sox10. Genes Dev 16:165-170. CrossRef Medline
Stolt CC, Lommes P, Sock E, Chaboissier MC, Schedl A, Wegner M (2003) The Sox 9 transcription factor determines glial fate choice in the developing spinal cord. Genes Dev 17:1677-1689. CrossRef Medline

Stolt CC, Lommes P, Friedrich RP, Wegner M (2004) Transcription factors Sox 8 and Sox 10 perform non-equivalent roles during oligodendrocyte development despite functional redundancy. Development 131:2349-2358. CrossRef Medline

Sun T, Echelard Y, Lu R, Yuk DI, Kaing S, Stiles CD, Rowitch DH (2001) Olig bHLH proteins interact with the homeodomain proteins to regulate cell fate acquisition in progenitors of the ventral neural tube. Curr Biol 11: 1413-1420. CrossRef Medline

Takebayashi H, Yoshida S, Sugimori M, Kosako H, Kominami R, Nakafuku M, Nabeshima Y (2000) Dynamic expression of basic helix-loop-helix Olig family members: implication of Olig2 in neuron and oligodendrocyte differentiation and identification of a new member, Olig3. Mech Dev 99:143-148. CrossRef Medline

Tanabe Y, William C, Jessell TM (1998) Specification of motor neuron identity by the MNR2 homeodomain protein. Cell 95:67-80. CrossRef Medline

Vallstedt A, Klos JM, Ericson J (2005) Multiple dorsoventral origins of oligodendrocyte generation in the spinal cord and hindbrain. Neuron 45: 55-67. CrossRef Medline

Viviano BL, Paine-Saunders S, Gasiunas N, Gallagher J, Saunders S (2004) Domain-specific modification of heparan sulfate by Qsulf1 modulates the binding of the bone morphogenetic protein antagonist Noggin. J Biol Chem 279:5604-5611. CrossRef Medline

Vokes SA, Ji H, McCuine S, Tenzen T, Giles S, Zhong S, Longabaugh WJ, Davidson EH, Wong WH, McMahon AP (2007) Genomic characterization of Gli-activator targets in sonic hedgehog-mediated neural patterning. Development 134:1977-1989. CrossRef Medline

Wojcinski A, Nakato H, Soula C, Glise B (2011) DSulfatase-1 fine-tunes Hedgehog patterning activity through a novel regulatory feedback loop. Dev Biol 358:168-180. CrossRef Medline

Yan D, Lin X (2009) Shaping morphogen gradients by proteoglycans. Cold Spring Harb Perspect Biol 1:a002493. CrossRef Medline

Zhang F, McLellan JS, Ayala AM, Leahy DJ, Linhardt RJ (2007) Kinetic and structural studies on interactions between heparin or heparan sulfate and proteins of the hedgehog signaling pathway. Biochemistry 46:3933-3941. CrossRef Medline

Zhou Q, Wang S, Anderson DJ (2000) Identification of a novel family of oligodendrocyte lineage-specific basic helix-loop-helix transcription factors. Neuron 25:331-343. CrossRef Medline

Zhou Q, Choi G, Anderson DJ (2001) The bHLH transcription factor Olig2 promotes oligodendrocyte differentiation in collaboration with $\mathrm{Nkx} 2.2$. Neuron 31:791-807. CrossRef Medline 